\title{
Home Equity Extraction and the Boom-Bust Cycle in Consumption and Residential Investment
}

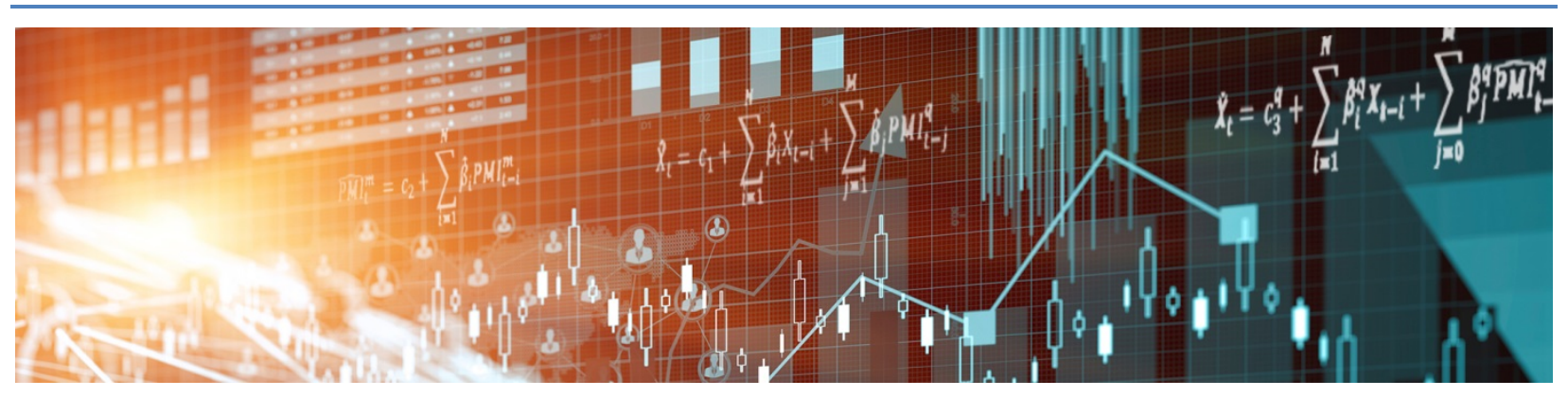

by Xiaoqing Zhou 
Bank of Canada Staff Working Paper 2018-6

February 2018

\title{
Home Equity Extraction and the Boom-Bust Cycle in Consumption and Residential Investment
}

\author{
by \\ Xiaoqing Zhou \\ Financial Stability Department \\ Bank of Canada \\ Ottawa, Ontario, Canada K1A 0G9 \\ xzhou@bankofcanada.ca
}




\section{Acknowledgements}

I thank Jason Allen, Michael Gelman, Joshua Hausman, Lutz Kilian, Frank Stafford, Dmitriy Stolyarov, Eleanor Wilking, and seminar participants at the Bank of Canada, the Institute of Social Research, the University of Michigan, and West Virginia University for helpful comments. The views in this paper are solely the responsibility of the author and should not be interpreted as reflecting the views of the Bank of Canada. 


\begin{abstract}
The consumption boom-bust cycle in the 2000s coincided with large fluctuations in the volume of home equity borrowing. Contrary to conventional wisdom, I show that homeowners largely borrowed for residential investment and not consumption. I rationalize this empirical finding using a calibrated two-goods, multiple-assets, heterogeneous-agent life-cycle model with borrowing frictions. The model replicates key features of the household-level and aggregate data. The model offers an alternative explanation of the consumption boom-bust cycle. This cycle is caused by large fluctuations in the number of borrowers and hence in total home equity borrowing, even though the fraction of borrowed funds spent on consumption is small.
\end{abstract}

Bank topics: Economic models; Housing; Credit and credit aggregates JEL codes: D1, E2, E3

\title{
Résumé
}

Le cycle d'expansion et de contraction de la consommation dans les années 2000 a coïncidé avec des fluctuations importantes du volume de prêts sur valeur domiciliaire. Nous montrons que, contrairement à ce qui est communément admis, les fonds empruntés par les propriétaires de logement visaient dans la plupart des cas à effectuer des investissements résidentiels et non des dépenses de consommation. Nous étayons ce résultat empirique au moyen d'un modèle de cycle de vie étalonné qui intègre deux biens, plusieurs actifs, des agents hétérogènes et dans lequel les emprunts font l'objet de frictions. Le modèle reproduit les principales caractéristiques des données sur les ménages et des données agrégées. Il fournit une explication alternative du cycle d'expansion et de contraction de la consommation. Ce cycle serait causé par de grandes fluctuations du nombre d'emprunteurs, et donc du volume total de prêts sur valeur domiciliaire, et ce, même si seulement une petite fraction des fonds empruntés est consacrée à des dépenses de consommation.

Sujets : Modèles économiques; Logement; Crédit et agrégats du crédit

Codes JEL : D1, E2, E3 


\section{Non-Technical Summary}

Between 2000 and 2013, the U.S. economy experienced large cyclical fluctuations in consumption. For example, the annual growth rate of personal consumption expenditures was about $2.7 \%$ before 2007 , fell to $-2.3 \%$ in the middle of 2009 , and then recovered to $1.6 \%$ by the end of 2013. In retrospect, many academics and policy analysts have pointed to increased borrowing by existing homeowners in the form of cash-out refinancing, second mortgages, or home equity lines of credit (HELOCs) as a likely explanation for this consumption boom-bust cycle. A common argument is that before the financial crisis, homeowners were able to extract equity from their homes in order to finance higher consumption. During the crisis, this borrowing channel dried up and consumption fell. This explanation is consistent with the aggregate data, which show that consumption co-moved with the volume of home equity cashed out during this period.

This conventional explanation, however, is difficult to reconcile with the microeconomic data. Using household-level survey data, I document that the most important use of extracted home equity in the 2000s was not consumer spending, but investment expenditures in the form of home improvements, purchases of a more expensive house, or purchases of a second home.

I rationalize this empirical finding using a calibrated two-goods, multiple-assets, heterogeneous-agent life-cycle model with borrowing frictions. The model replicates key features of the household-level data as well as the aggregate data. The model offers an alternative explanation of the consumption boom-bust cycle. It suggests that the boom-bust cycle in aggregate consumption and in residential investment in the 2000s was caused by large fluctuations in the number of borrowers and hence in total home equity borrowing rather than by borrowers spending a larger

fraction of their borrowed funds on consumption. I quantify the contribution of the borrowing channel by two counterfactual experiments. My evidence suggests that this class of life-cycle models, which recently has gained in popularity, is suitable for policy analysis more generally. 


\section{Introduction}

Between 2000 and 2013, the U.S. economy experienced large cyclical fluctuations in consumption. In retrospect, many academics and policy analysts have pointed to increased borrowing by existing homeowners, for example, in the form of cash-out refinancing, second mortgages, or home equity lines of credit (HELOCs), as a likely explanation for this consumption boom-bust cycle (see, e.g., Mian and Sufi (2011, 2014), Mian et al. (2013), and Bhutta and Keys (2016)). A common argument is that, before the financial crisis, homeowners were able to extract equity from their homes in order to finance higher consumption. During the crisis, this borrowing channel dried up and consumption fell. This explanation is consistent with the aggregate data. As shown in the left panel of Figure 1, consumption roughly co-moved with the volume of home equity cashed out during this period.

This conventional explanation, however, is difficult to reconcile with the microeconomic data. Household-level survey data suggest that the most important use of extracted home equity was not consumption, but housing investment in the form of home improvements, home upgrades, or purchases of a second home. ${ }^{1}$ This point is illustrated in Figure 2, which shows the change in household consumption expenditures (left) and the change in housing investment expenditures (right) for a one-dollar increase in mortgage debt, estimated based on data from the Panel Study of Income Dynamics (PSID). Whereas the resulting increase in consumption never exceeded 5 cents, the increase in housing investment was on average 40 cents.

Figure 2 raises two questions. First, how can we reconcile the household-level and aggregate data on the relationship between U.S. mortgage debt and consumption? Since increased mortgage debt did not stimulate consumption through the intensive margin, it must have raised consumption through the extensive margin. Put differently, if the increase in consumption for a given dollar increase in mortgage debt is small, fluctuations in aggregate consumption can only be explained by changes in the number of borrowers and hence in the total amount borrowed. This is consistent with the aggregate data. According to the Freddie Mac Quarterly Cash-out Refinance Report, the share of cash-out refinancing among all refinanced mortgages rose from $48 \%$ in 1998 to $87 \%$ in 2006, before dropping to $14 \%$ in 2012. Likewise, in the PSID, 35\% of existing homeowners in the

\footnotetext{
${ }^{1}$ Improvements to residential structures accounted for $30 \%$ of residential investment in the National Income and Product Accounts (NIPA) between 1999 and 2015. They consist of (i) additions and alterations, such as the addition of another floor to an existing house, the finishing of basements and attics, the remodeling of kitchens or bathrooms, and the addition of swimming pools or garages, and (ii) major replacements such as new roofs, water heaters, furnaces, and central air conditioners. These expenditures prolong the life of the structure or add to its value. Routine maintenance and repair work are excluded.
} 
United States increased their mortgage debt between 2001 and 2005, whereas this number fell to $16 \%$ in 2013. Moreover, among existing homeowners, young homeowners were particularly prone to increasing their mortgage debt.

The second question raised by Figure 2 is how to explain the patterns in the household-level and aggregate data. I show that a calibrated life-cycle model (i) rationalizes the strong positive correlation between increased mortgage debt and spending on housing investment at the household level; (ii) replicates the response of mortgage borrowing to aggregate shocks such as an unexpected increase in house prices or a mortgage rate reduction; and (iii) captures key features of the boom-bust cycles in U.S. aggregate consumption and residential investment shown in Figure 1.

The choice of this life-cycle model is motivated by two sets of empirical results based on PSID data from 1999 to 2015. The first set of results relates to how existing homeowners spend their borrowed funds when increasing their mortgage debt. Consistent with earlier studies, I document that for homeowners who do not change their primary residence, spending on home improvements is the most important use of home equity loans. ${ }^{2}$ In addition, I provide new evidence on the behavior of repeat sellers. I show that for these homeowners, increased mortgage debt is primarily used to finance the purchase of a more expensive home. Moreover, I show that increased mortgage debt is also associated with buying a second home or investing in real estate. These results together establish a strong correlation between mortgage borrowing and housing investment expenditures of existing homeowners. Of equal importance for the choice of the model is the fact that this correlation is strongest among young homeowners for all types of housing investment. ${ }^{3}$ The second set of empirical findings consists of estimates of the effect of house price shocks and mortgage rate shocks on borrowing. Using household-level variation in house prices and mortgage rates, I show that both shocks strongly stimulate mortgage borrowing through the extensive margin. Moreover, these responses differ by age. The response to a positive house price shock is strongest among young homeowners aged 26 to 35, and is monotonically declining with age, whereas the response to a mortgage rate reduction is largest among homeowners aged 36 to 45 .

I show how these two sets of results can be explained by a two-goods, multiple-assets, heterogeneous-agent life-cycle model with collateral constraints and borrowing frictions. For this purpose, I adapt the model of Berger et al. $(2015,2017)$ to study the importance of life-cycle features in explaining the demand for liquidity and housing investment. The model has two consumption

\footnotetext{
${ }^{2}$ See, e.g., Canner et al. (2002), Brady et al. (2000), Cooper (2009), Greenspan and Kennedy (2007), Nam (2015), Benito and Power (2004), and Smith (2010).

${ }^{3}$ For related discussion of households upgrading their homes, see Ortalo-Magne and Rady (1999, 2006).
} 
goods: non-housing consumption and housing services. Households face uninsured labor income risks. There are three ways to save: increasing liquid assets, paying down mortgage debt, and investing in housing. Households are allowed to use their homes as collateral to borrow, but borrowing cannot exceed the value of the house. In addition, raising the mortgage debt level is subject to adjustment costs. Unlike an infinitely-lived representative household model, this life-cycle model captures extensive and intensive margins of adjustment that arise from endogenous borrowing decisions of heterogeneous agents. It also speaks to the heterogeneity across age groups in the micro data. The model is calibrated to U.S. data.

At the household level, the model rationalizes the strong correlation between increased mortgage debt and housing investment expenditures. ${ }^{4}$ This correlation arises due to the life-cycle features of the model even in the absence of aggregate shocks. In the stationary equilibrium, young households start their life with small homes. This implies that the marginal utility of housing consumption is high and that they want to invest in housing. In the absence of mortgage adjustment costs, housing investment would be made continuously, as homeowners increase their mortgage debt. Mortgage adjustment costs, however, prevent homeowners from raising their debt continuously. As a result, homeowners delay investing until they can borrow a large amount of cash. This explains why in the data homeowners who increase their mortgage debt tend to spend largely on housing investment.

This behavior is amplified by shocks in the housing market. For example, in the model, an unexpected increase in house prices or an unexpected reduction in the mortgage rate drives some homeowners, who otherwise would not do so, to raise their borrowing and to spend much of the borrowed funds on housing investment. The model helps quantify these impacts. I show that both shocks stimulate existing homeowners to borrow, but the age profile of this response depends on the shock. Specifically, a positive house price shock raises the collateral value immediately. Hence, the age profile of the borrowing response declines with age, consistent with the empirical estimates. The response of borrowing to a mortgage rate reduction, however, is not monotonic in age. It peaks at age $36-45$, in line with the empirical evidence. This is because a decline in the mortgage rate does not raise the collateral value immediately, so it makes little difference for young homeowners whose current debt is almost at the collateral value. It is those aged 36-45 who have few liquid assets but have accumulated substantial home equity who benefit the most from a mortgage rate

\footnotetext{
${ }^{4}$ This correlation does not arise in models that treat home equity as a high-return illiquid asset and do not incorporate housing as a consumption good. These models naturally imply that liquidity-constrained households extract home equity to smooth consumption (see, e.g., Hurst and Stafford (2004), Beraja et al. (2015), and Li (2009)).
} 
reduction. For each of these shocks, both consumption and housing investment increase, but the response of housing investment is much larger than that of consumption.

I also examine to what extent this life-cycle model is able to explain the evolution of aggregate consumption and residential investment in the U.S. economy during the 2000s. For this purpose, I simulate the evolution of these variables by feeding into the model historical real house price indices, the real cost of residential structures, and real mortgage rates. I then compare the simulated data with the actual U.S. data. I show that the model captures key features of the U.S. boom-bust cycle. During the boom, as house prices increased and the mortgage rate declined, housing stock was built due to the investment made by existing homeowners, especially young homeowners. The growing housing stock facilitated more borrowing which in turn financed spending on both housing investment and consumption. In the subsequent bust period, when house prices fell sharply, fewer households were able to borrow. As a result, housing investment declined, collateral value shrank, mortgage borrowing decreased, and consumption slumped.

Given its ability to capture both the micro and macro evidence, I use the model to conduct two policy experiments that help quantify the role of the housing collateral channel in transmitting aggregate shocks. The first experiment shows that if houses were not collateral assets, the volatility of consumption between 2000 and 2010 would have been reduced by $90 \%$. The second experiment shows that if the mortgage rate had stayed the same as in the year 2000, consumption volatility between 2000 and 2010 would have been reduced by $75 \%$. These experiments illustrate the important role of the collateral channel for cyclical fluctuations.

The remainder of the paper is organized as follows. Section 2 highlights the patterns in the household-survey data that motivate the choice of the life-cycle model and presents the empirical results that are used for model evaluation. Section 3 discusses the life-cycle model, and Section 4 describes its calibration. In Section 5, I evaluate the performance of the model in matching the micro-level evidence, including the average life-cycle choices across all homeowners, and the heterogeneous spending patterns by households' borrowing status and by their age. Section 6 compares the impulse responses in the model with the empirical estimates. Section 7 assesses to which extent the calibrated model can explain the boom-bust cycle in U.S. consumption and residential investment in the 2000s. I also conduct two counterfactual analyses to quantify the role of the housing collateral channel in transmitting aggregate shocks during this period. Section 8 concludes. 


\section{$2 \quad$ Empirical Evidence}

In this section, I present two sets of empirical findings based on PSID data that in conjunction motivate the theoretical analysis in Section 3. First, I document the spending patterns associated with increased mortgage debt, and the heterogeneity of these patterns by age. I find that existing homeowners tend to increase their mortgage debt mainly to finance expenditures on housing investment rather than personal consumption, and that this tendency is strongest among young homeowners. Second, I estimate the effect of a positive house price shock and of a mortgage rate reduction on household borrowing behavior. While both shocks increase the probability of households increasing their mortgage debt, the age profile of the responses depend on the shock. The response of borrowing to a positive house price shock declines with age, but the response to a mortgage rate reduction peaks for young to middle-aged households.

\subsection{Data and Sample Selection}

The main data source is the PSID biennial family survey from 1999 to 2015. The survey collects data from approximately 7,000 households every other year. The PSID sample is representative of the U.S. population and provides detailed information on household wealth, mortgages, income, and expenditures. PSID data are ideal to study the relation between mortgage borrowing and consumer spending because their long panel structure allows one to link consumer expenditures to the change in mortgage debt. The Survey of Consumer Finance (SCF), in contrast, collects data on household wealth, but not on expenditures, making it unsuitable for my purpose. ${ }^{5}$ The Consumer Expenditure Survey $(\mathrm{CE})$, on the other hand, collects detailed expenditure data over a short panel of four quarters, but does not reflect the change in the mortgage debt level. Therefore, it cannot be used to identify changes in household borrowing. ${ }^{6}$ Moreover, it does not follow households who moved after entering the sample. This means that housing investment expenditures only include those purchases of a second home and home improvements made by non-movers.

I apply the following sample-selection criteria. First, I focus on households of working age, whose head is between 26 and 65 years old. Second, I focus on existing homeowners, because they have the ability to use their homes as collateral to borrow and finance their expenditures.

\footnotetext{
${ }^{5}$ In addition, SCF is a cross-sectional survey, although recently a two-period panel has become available in which respondents to the 2007 survey were reinterviewed in 2009. Based on the work of Juster et al. (1999) and Pfeffer et al. (2016), estimates of total net worth using the PSID and the SCF are similar throughout most of the distribution, with the largest difference concentrated in the 1 to $2 \%$ of wealth distribution. This difference is primarily due to the SCF oversampling households with high wealth.

${ }^{6}$ The CE provides information on whether a mortgage loan is refinanced, but does not distinguish between cash-out refinancing and interest-rate (no cash-out) refinancing.
} 
This means that renters are excluded. ${ }^{7}$ I also exclude first-time home buyers because the increase in their mortgage debt (from zero) is by construction completely used to finance their housing investment. Third, I exclude households owning farms or businesses. Fourth, to reduce possible errors in the survey data, I exclude households having negative total income or having a home value below $\$ 5,000$. A detailed description of the data and variables can be found in Appendix A.

I identify homeowners who increase their mortgage debt as homeowners whose total mortgage balance tied to the primary residence increases by more than $5 \%$ between two interviews, provided the increase exceeds $\$ 1,000 .{ }^{8}$ This criterion was used by Bhutta and Keys (2016) to define home equity extractors. In the case of homeowners who do not change their residence, the increase in mortgage debt coincides with a reduction in home equity. If homeowners sell their old home and purchase a new home, in contrast, this equivalence breaks down. In the latter case, it makes sense to focus on the increase in mortgage debt, which drives homeowners' spending decisions, rather than the change in home equity. Given that most homeowners do not change their residence, in this paper, I will use the terms increase in mortgage debt and home equity extraction interchangeably.

Columns (3) to (6) in Table 1 show the average home value of existing homeowners, the average of their mortgage balance (conditional on having a mortgage), the percentage of homeowners who increased their mortgage debt, and the average increase in the mortgage balance (conditional on increasing the mortgage debt). Mortgage balances increased over time until 2013. Home values experienced a boom-bust cycle similar to the national house price index. The share of homeowners who increased their mortgage debt was on average 30\% between 2001 and 2007, before dropping to 16\% around 2011. The change in mortgage debt experienced a cycle similar to that in house prices. The last four columns of Table 1 show the expenditures on housing investment and consumption of those who increased their mortgage debt and of those who did not. On average, the expenditures on housing investment of those who increased their mortgages are almost six times as high as of those who did not. The expenditures on consumption, however, do not differ much.

While Table 1 already shows a strong correlation between increased mortgage debt and housing investment expenditures, it does not take into account confounding factors such as demographics, income and wealth holdings that may cause some households to increase their mortgage debt and to spend on housing investment. Nor does it reveal the heterogeneity of this correlation across

\footnotetext{
${ }^{7}$ This approach is motivated by the observation in Mian and Sufi (2011) that the aggregate consumption dynamics of interest are driven by existing homeowners.

${ }^{8} \mathrm{I}$ use the mortgage balance tied to the primary residence because the PSID survey does not collect the mortgage information of a second home or real estate property.
} 
homeowners. In addition, it does not distinguish between different types of housing investment and consumer expenditures. Next, I provide empirical results based on regression analysis that establish this conditional correlation and its heterogeneity across households and across expenditure types.

\subsection{Expenditures Associated with Increased Mortgage Debt}

This section documents the spending patterns associated with increased mortgage debt. First, I show that homeowners who increase their mortgage debt are more likely to invest in housing by purchasing a more expensive home, by making home improvements, or by buying a second home. Second, I compare the growth of expenditures over a wide range of categories between those who increase their mortgage debt and those who do not. I find that the growth of expenditures on housing explains almost all of the differences in the expenditure growth between these two groups. Finally, I estimate the fraction of the increased debt spent on different items.

\subsubsection{Mortgage Borrowing and Housing Investments}

Homeowners who increase their mortgage debt may invest in housing in three ways. First, homeowners may sell their old residence and purchase a higher-quality, more expensive home. ${ }^{9}$ Such a move-up type of investment occurs when the price of the new home is larger than the selling price of the old home. ${ }^{10}$ Second, homeowners may make improvements to their current residence. I define an improvement type of investment as homeowners spending more than $\$ 10,000$ on improvements, remodeling, or additions. ${ }^{11}$ Third, homeowners may purchase a second home or may make a net positive investment in real estate.

I use a logit specification to examine households' tendency to use home equity to finance these different types of housing investment. I also estimate this tendency by age group. The specification is

$$
\operatorname{Prob}\left(\text { Invest }_{i, t}=1\right)=\alpha_{0}+\alpha_{1} \text { Extract }_{i, t}+X_{i, t} \alpha_{2}+W_{i, t-1} \alpha_{3}+\alpha_{4} \Delta y_{i, t}+\gamma_{t}+\varepsilon_{i, t},
$$

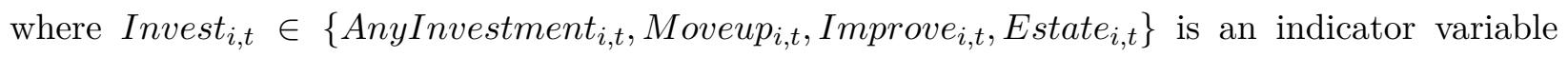
equal to 1 if household $i$ at time $t$ makes a certain type of housing investment. AnyInvestment denotes any of the three types of housing investment. Moveup, Improve and Estate denote the move-up type, the improvement type and the real estate type of investment, respectively.

\footnotetext{
${ }^{9}$ In the PSID data, among those under age $65,80 \%$ of those who sold an old home and purchased a new one upgraded to a more expensive one.

${ }^{10}$ I assume that the price of a home represents the quality of the home to the buyer. This assumption also facilitates the quantification of investment expenditures.

${ }^{11}$ The PSID restricts attention to home improvements, remodeling, and additions that cost at least $\$ 10,000$ to capture the major improvement expenditures rather than small maintenance or repair costs.
} 
Extract $_{i, t}=1$ if household $i$ at time $t$ increases the mortgage balance by more than $5 \%$ and by more than $\$ 1,000$, and equal to zero otherwise. $X_{i, t}$ is a vector of household characteristics (age, age-squared, change in family size), $\triangle y_{i, t}$ denotes the growth rate of income, $W_{i, t-1}$ is a vector of variables capturing the financial conditions of the household (lagged income, lagged liquid assets, and lagged illiquid assets), and $\gamma_{t}$ is a set of year dummies, designed to capture aggregate time trends such as changes in interest rates and business cycle fluctuations.

Throughout the paper, the estimates of the logit model coefficients are transformed to marginal effects. Table 2 contains the estimates of equation (1). Panel (i) shows the change in the propensity to make any type of housing investment. Column (1) of this panel shows that on average, those who increase their mortgage debt are $12.3 \%$ more likely to make a housing investment. In the PSID data, the unconditional propensity of making any type of housing investment is $16.3 \%$. This propensity is much higher for homeowners who increase their debt (about 29\%), compared with homeowners who do not increase their debt (12\%). Controlling for household characteristics reduces the difference to $12.3 \%$, as shown in column (1), but the difference is still large. The next four columns show that the propensity to invest in homes is monotonically decreasing with age. It is highest for the youngest households, with $21 \%$.

Panels (ii) to (iv) examine the change in the propensity to make certain types of housing investment when a homeowner borrows more. Column (1) of panel (ii) shows that the probability of making a move-up type of investment is $8.5 \%$ higher for those who increase their mortgage debt than those who do not. In other words, when existing homeowners increase their mortgage debt to finance the purchase of a new house, they tend to choose a more expensive house. This tendency monotonically declines with age.

Column (1) of panel (iii) shows that the probability of making an improvement type of investment is $5 \%$ higher for those who increase their mortgage debt than for those who do not. Estimating this relation by age shows that this probability is highest among young homeowners who raise their mortgage debt. One may be concerned that these results are driven by homeowners who are moving up to a more expensive home. To address this concern, I also restricted the sample to households who have not changed their primary residence for at least four years before the interview and continued to stay for at least two more years in this residence. The estimated marginal effects are almost the same as in panel (iii). This is not surprising given that the correlation between selling a home and making a home improvement is low (0.08). ${ }^{12}$

\footnotetext{
${ }^{12}$ I also examine whether making home improvements is associated with rising consumer credit (credit card balances
} 
Finally, column (1) of panel (iv) shows that homeowners who increase their mortgage debt also are $1.2 \%$ more likely to buy a second home, or to invest in real estate. This tendency is strongest among homeowners aged 36-45, and then declines with age. As an additional robustness check, I verify that there is no positive relationship between increased mortgage debt and investments in other assets, such as the value of stock holdings or retirement accounts. ${ }^{13}$

\subsubsection{Differences in Expenditure Growth}

I now compare the growth of expenditures for different categories between those who increase their mortgage debt and those who do not. Historically, the PSID survey collects information only on food and housing expenditures. Since 1999, the survey added questions about other expenditures such as transportation, gasoline, utilities, education, health, and child care. According to Li et al. (2010), these expenditures cover more than $70 \%$ of the total outlays measured in the CE. I group these expenditures into personal consumption expenditures and housing investment expenditures. Personal consumption expenditures consist of spending on non-durable goods (food and gasoline), durable goods (vehicle purchases), and services (utilities, education, health, child care, vehicle lease, public transportation, parking, vehicle repair, vehicle insurance, homeowner insurance, property tax, and mortgage payments). Housing investment expenditures consist of investment through trading homes (the difference in the price of the current home and the selling price of the old home), expenditures on home improvements, remodeling and additions, and purchases of a second home or real estate. All expenditures are converted to 2009 dollars using the CPI. I normalize the growth of each expenditure by total expenditures in the previous period. The linear regression model is

$$
\frac{\triangle \text { Expenditures }_{i, t}^{k}}{\text { TotalExpenditures }_{i, t-1}}=\beta_{0}^{k}+\beta_{1}^{k} \text { Extract }_{i, t}+X_{i, t} \beta_{2}^{k}+W_{i, t-1} \beta_{3}^{k}+\beta_{4}^{k} \triangle y_{i, t}+\gamma_{t}^{k}+\varepsilon_{i, t}^{k}
$$

where $\triangle$ Expenditures $i_{i, t}^{k}$ denotes the change (in dollars) in the expenditures of category $k$.

or loans from relatives) by replacing Extract $_{i, t}$ with an indicator of increased consumer debt. The relationship is not significant at the $10 \%$ level.

${ }^{13}$ Mian and Sufi (2011) suggest that (i) increased mortgage debt due to house price appreciation between 2002 and 2006 was not used for purchasing bigger homes, (ii) nor it was used for purchasing investment properties. They support their first point by evidence that house price appreciations are not correlated with the probability of moving. They support their second point by evidence that house price appreciations are not correlated with the change in the number of mortgage accounts owned by a homeowner. Closer inspection casts doubt on this reasoning. First, moving to another zip code does not necessarily mean that a homeowner purchases a new home. In the PSID data, among homeowners who move, only half trade their homes. Second, Mian and Sufi assume that an increase in the number of mortgage accounts is associated with purchases of real estate. This assumption is questionable. For example, homeowners can take a second mortgage, which by definition raises the number of mortgage accounts without changing the real estate position. Likewise, homeowners can consolidate their mortgage debt by reducing the number of mortgage accounts, again without affecting real estate investment. In the PSID data, the correlation between changes in the number of mortgage accounts and changes in real estate investment is -0.0005 . 
TotalExpenditures ${ }_{i, t-1}$ denotes total expenditures (in dollars) in the previous period. Other variables are defined as in equation (1). Note that $\beta_{1}^{k}$ measures the difference in the growth of expenditure category $k$, between those who increase their mortgage debt and those who do not.

Table 3 shows the estimates of equation (2). The growth rate of total expenditures of homeowners who increase their mortgage is almost 20 percentage points higher than those who do not. ${ }^{14}$ The difference in personal consumption expenditure growth explains about 8 percentage points, and the growth in housing investment expenditures explains the remaining 12 percentage points. I then estimate the contribution of each category of personal consumption expenditures. I find that the service category explains almost all of the effect on consumption. ${ }^{15}$ A closer look at the service category shows that the growth in mortgage payments accounts for almost all of the effect on the service expenditure growth. This result is not surprising, given that increased mortgage debt, associated either with a new home or with home equity cashed out, raises mortgage payments. Among housing investment expenditures, the growth of the move-up type of investment contributes most to the difference in housing investment expenditure growth.

I also examine whether $\beta_{1}^{k}$ differs across age for each expenditure category $k$. For personal consumption expenditures, the only category that shows a significant declining age profile is mortgage payments. This result is expected. In the PSID data, among homeowners who increase their mortgage debt, young homeowners increase their debt the most and hence experience the largest growth in mortgage payments. The difference in the growth of housing investment exhibits strong heterogeneity across age. Table 4 shows a difference of 28 percentage points for the youngest homeowners, and around 6 percentage points for the next two age groups. I also examine the age profile of this difference by investment type. Both the move-up type and the improvement type of investment show a declining age profile overall, except for a noisy estimate for age 56-65 in the move-up type investment. This noisy and insignificant estimate explains the noisy estimate for the last age group in Table 4. I do not find a significant age profile for real estate investment. One reason is the small sample of real estate investors and second-home buyers in the PSID data. In the data, only $3 \%$ of homeowners make such investments.

One may be concerned that personal consumption expenditures measured in the PSID survey

\footnotetext{
${ }^{14}$ In the PSID data, the growth rate of total expenditures is about $9.6 \%$ for all homeowners. On average, the growth rate of total expenditures of those who increased their mortgage debt is $25 \%$, and $4.5 \%$ for those who did not increase their mortgage debt.

${ }^{15}$ Although I do not find any difference in the overall durables' spending, I do find that homeowners who increase their mortgage balance are more likely to purchase a vehicle.
} 
as shown in Table 3 may not capture the full scope of consumer spending. In 2005, the PSID survey added questions regarding the following expenditures: (1) furniture, trips, and recreation spending, which I include in durables; (2) clothing, which I categorize as non-durables; and (3) telephone, internet, and home repair services, which I categorize as services. With these added expenditures, the PSID captures almost all the expenditures measured in the CE (see Andreski et al. (2014)). Using data from 2005 onwards, I find that the personal consumption expenditures used in Table 3 account for $83 \%$ of the expanded personal consumption expenditures. I then estimate the same regression models in Tables 3 and 4 for the PSID data from 2005 onward. The results are very similar.

\subsubsection{Increased Spending out of Increased Mortgage Debt}

I now quantify the intensive margin that captures spending increases for a given amount of borrowing. Specifically, I estimate, for a one-dollar increase in mortgage debt, the change in different expenditure categories. ${ }^{16}$ For each category, I also estimate the heterogeneity of this change across age groups. The regression model is specified as

$$
\triangle \text { Expenditures }_{i, t}^{k}=\delta_{0}^{k}+\delta_{1}^{k} \triangle b_{i, t}+X_{i, t} \delta_{2}^{k}+W_{i, t-1} \delta_{3}^{k}+\delta_{4}^{k} \triangle y_{i, t}+\zeta_{t}^{k}+u_{i, t}^{k},
$$

where $\triangle$ Expenditures $_{i, t}^{k}$ denotes the change (in dollars) in expenditure category $k . \triangle b_{i, t}$ denotes the change (in dollars) in the mortgage balance. Both variables are converted to 2009 dollars using the CPI. Other variables are defined as in equation (1).

Table 5 shows the estimates of equation (3). Half of the increased mortgage debt goes to total expenditures, among which personal consumption expenditures account for 12 cents and housing investment expenditures account for the remaining 38 cents. ${ }^{17}$ This result is consistent with Table 3. First, the major component driving personal consumption expenditures is mortgage payments. Second, households spend a substantial fraction of their mortgage debt on housing investment expenditures, both on the move-up type and on the improvement type.

\footnotetext{
${ }^{16}$ In related work, Cooper (2009), using the 1999-2009 PSID data, investigates the change in spending for a one-dollar increase in mortgage debt. His estimates, however, are not comparable across spending categories or years. For example, in estimating spending on home improvement, he drops all households making zero improvement that correspond to almost $90 \%$ of the sample (Table 5 in his paper), which results in an overestimate of the home improvement spending.

${ }^{17}$ The remaining 50 cents may be attributed to two other outlays. First, households may borrow, for example, to pay for the college tuition of their children or grandchildren, or for the hospital expenses of parents or grandparents. These outlays are not recorded under consumption or housing investment in the PSID. Second, households may deposit the borrowed funds to their checking or savings accounts or invest in other assets. While I do not find significant changes in liquid savings or investment accounts, this finding may simply reflect the fact that the PSID tends to under-report liquid savings. According to Pfeffer et al. (2016), the average amount in the checking/savings accounts reported by SCF households is $32 \%$ higher than for PSID households, even after excluding the SCF households in the top distribution of wealth.
} 
Next, I examine the heterogeneity of the spending changes across age groups for each category. I do not find significant heterogeneity for personal consumption expenditures. The change in housing investment expenditures, however, shows strong heterogeneity by age. As shown in Table 6, young homeowners spent 63 cents on housing investment for a one-dollar increase in mortgage debt, but this number falls to 13 cents at age 56-65. A further decomposition of housing investment expenditures shows that both the move-up type and the improvement type investment exhibit a similarly declining age profile.

Finally, I use this regression model to quantify the intensive margin of household spending on consumption (excluding mortgage payment) and on housing investment during 1999 to 2015. The reason for excluding mortgage payments is that non-housing consumption in standard models does not incorporate mortgage payments. The results are plotted in Figure 2. During this period, the increase in consumption never exceeded 5 cents, even at the peak of the housing boom in 2005. The increase in housing investment expenditures, in contrast, was on average 40 cents.

As a robustness check, I also restricted the sample to homeowners who do not change their primary residence during a given interview period, so that an increase in mortgage debt is equivalent to a reduction in home equity. In this case, housing investment includes only home improvements and purchases of real estate. I re-estimated the regression models that are applicable. The results are consistent with the key observations (i) that home equity extraction is associated with housing investment expenditures (mainly home improvement), (ii) that the increase in housing investment expenditures is much larger than the increase in consumption expenditures for a given amount of home equity loans, and (iii) that these patterns are strongest among young homeowners.

Based on these results, I conclude that increased mortgage debt at the household level was directly responsible for the cycle in aggregate residential investment, and that the cycle in aggregate consumption cannot be caused by the intensive margin. Thus, increased borrowing must have affected aggregate consumption mainly through the extensive margin. Next, I show that shocks in the housing market, such as an increase in house prices or a reduction in mortgage rates, have a large effect on the extensive margin, represented by the borrowing propensity.

\subsection{Response of Borrowing to Shocks in the Housing Market}

In this section, I quantify the extent to which shocks in the housing market, such as a positive house price shock or a reduction in mortgage rates, can stimulate mortgage borrowing on the extensive margin. I estimate the propensity that an existing homeowner increases his mortgage 
debt in response to these shocks. I then estimate the heterogeneity of this propensity across age groups. I find that both shocks have a large stimulative effect on the borrowing propensity. However, the response to a positive house price shock declines monotonically with age, whereas the response to a mortgage rate reduction is largest among those aged 36-45.

\subsubsection{House Price Shocks}

To quantify the effect of house price shocks on the borrowing propensity, I estimate a logit model that utilizes cross-sectional household-level variation in house prices. ${ }^{18}$ I control for year dummies to remove confounding effects from other aggregate shocks (such as interest rates and the expectation toward future income). I control for changes in income, household financial conditions, and demographics to remove the confounding effects at the household level. The identifying assumption is that conditional on these variables, variation in the growth rate of house prices is exogenous with respect to the household's borrowing decision. The estimated logit model is

$$
\operatorname{Prob}\left(\operatorname{Extract}_{i, t}=1\right)=\theta_{0}+\theta_{1} \triangle h p_{i, t}+X_{i, t} \theta_{2}+W_{i, t-1} \theta_{3}+\theta_{4} \triangle y_{i, t}+\gamma_{t}+\nu_{i, t},
$$

where $\triangle h p_{i, t}$ denotes the growth rate of the real house price of household $i$ in time $t$. The other variables are defined as in equation (1).

Column (1) in Table 7 shows that a $1 \%$ increase in real house prices raises the probability that a homeowner increases his mortgage debt by 0.27 percentage points. The aggregate impact of house price shocks based on this estimate is large. In the PSID data, from 2003 to 2005, the average real house price growth was $13 \%$. This implies that about $3.5 \%$ of existing homeowners increased their borrowing, who otherwise would not have done so. Given that the historical share of homeowners who increase their mortgage debt is $25 \%$, this represents a $15 \%$ increase in the share. The remaining four columns of the table show significant heterogeneity in the borrowing response, which is monotonically decreasing with age. Among the youngest homeowners, a $1 \%$ increase in real house prices raises the borrowing propensity by 0.5 percentage points, almost double the average effect.

Intuitively, a positive house price shock stimulates borrowing by relaxing the collateral constraint, a mechanism emphasized by a large theoretical literature on the transmission of

\footnotetext{
${ }^{18}$ In related work, Mian and Sufi (2014) estimate the change in zip code cash-out refinancing mortgage share in response to local house price growth. The key difference here from their estimate is that I consider the propensity of borrowing not only in the form of cash-out refinancing, but in other forms such as a second mortgage, a HELOC, or a new larger loan. Their estimate shows that a $1 \%$ house price growth increases the cash-out refinancing propensity by $0.15 \%$, whereas my estimate shows that a $1 \%$ house price growth increases the overall borrowing propensity by $0.27 \%$. Given that in the PSID data, cash-out refinancing accounts for about $50 \%$ of all forms of home equity extraction, my estimate is consistent with theirs.
} 
aggregate shocks. ${ }^{19}$ An empirically testable implication of this mechanism is that homeowners who are approaching or are at their borrowing limit are more likely to increase their borrowing in response to a positive house price shock than are other homeowners. To illustrate this collateral effect, I use a household's loan to value ratio (LTV) in the previous period to measure how tight the collateral constraint is. The LTV is defined as the ratio of the total mortgage balance over the house price. I include $L T V_{i, t-1}$ and an interaction term, $L T V_{i, t-1} \times \triangle h p_{i, t}$, in model (4) to capture the differential response to the house price shock. The results are shown in Table 8. The positive coefficient on the interaction term in column (1) shows that for the same house price growth, the borrowing of those who have a higher LTV in the previous period responds more. A closer look at these responses by age reveals that the collateral effect largely explains the age profile of the borrowing responses. The large response of young homeowners shown in Table 7 is mainly driven by those who have a high LTV in the previous period.

Using household-level data has the advantage of controlling for aggregate confounding factors. However, one may be concerned that borrowing decisions at the individual level may cause an increase in a household's house price. For example, young homeowners who have a small house want to invest in their home. Since they are often short of cash, they may take a home equity loan to finance such spending, as suggested in Section 2.2. If their investment spending effectively raises the market value of the house, then the observed house price growth may in fact be caused by increased borrowing. The estimation hence suffers from a reverse causality problem. To address this concern, I include an indicator of whether the homeowner buys a more expensive home, and an indicator of whether the homeowner makes home improvements. After controlling for these two factors, the average response declines to 0.2 , which is still three quarters of the original estimate. The response of each age group also reduces slightly, but the age profile still shows a strong monotonically declining pattern across age.

\subsubsection{Mortgage Rate Shocks}

I now examine the impact of a mortgage rate reduction on the propensity to borrow. I focus on homeowners who have mortgages, because they report the rate at which they repay their mortgages. I use household-level variation in the mortgage rate in the previous period to determine the response of mortgage borrowing in the current period. There are two reasons to focus on this variation. First, households respond to the difference between their own mortgage rate (measured as their

\footnotetext{
${ }^{19}$ See, e.g., Iacoviello (2005), Iacoviello and Pavan (2013), Chen et al. (2013), Berger et al. (2017), Kaplan et al. (2017).
} 
previous-period mortgage rate) and the prevailing market rate (which is the same for all households and subsumed in the time fixed effect). Second, using households' previous-period rate rather than their current-period rate mitigates concerns about reverse causality. ${ }^{20}$

I control for the growth rate of the house price, the growth rate of income, household financial conditions, and demographics. The identifying assumption is that conditional on these variables, the variation in the level of the previous-period mortgage rate is exogenous to household borrowing decisions. The model is specified as

$$
\operatorname{Prob}\left(\operatorname{Extract}_{i, t}=1\right)=\eta_{0}+\eta_{1} r_{i, t-1}^{b}+\eta_{2} \triangle h p_{i, t}+X_{i, t} \eta_{3}+W_{i, t-1} \eta_{4}+\eta_{5} \triangle y_{i, t}+\gamma_{t}+e_{i, t},
$$

where $r_{i, t-1}^{b}$ denotes the mortgage rate of household $i$ in time $t-1$. Other variables are defined as in equation (4). Table 9 shows the results for the impact of a mortgage rate reduction. Column (1) shows that, if homeowner X's mortgage rate in the previous period is 1 percentage point higher than homeowner Y's, the probability that X borrows more in the current period is 0.85 percentage points higher than Y's.

The remaining four columns show the age profile of this response. Unlike the age profile of the response to house price shocks, the response to a mortgage rate reduction peaks for the age group 36-45. The intuition is that a lower mortgage makes little difference for young homeowners whose current debt is almost at the collateral value, since the lower mortgage rate does not increase the collateral value immediately. It is those aged 36-45 who have few liquid assets but have accumulated substantial home equity who benefit the most from a mortgage rate reduction. This may be seen from the share of home equity in total wealth by age group. In the data, homeowners of age 36-45 have the largest share of their wealth tied to their home equity. Note that for homeowners with mortgages, the effect of a positive house price shock is even larger.

Finally, one may be concerned that the previous-period mortgage rate may reflect unobserved

\footnotetext{
${ }^{20}$ In related work, Bhutta and Keys (2016) estimate the change in home equity extraction rate in response to a mortgage rate drop. The key difference here from their estimate is that I consider the propensity of borrowing not only of homeowners who do not change their primary residence, but of all existing homeowners, including repeat sellers. Their estimate shows that a 1 percentage-point drop in the mortgage rate (roughly 1 standard deviation) increases the extraction rate by 3 percentage points, whereas my estimate shows that the borrowing propensity increases by about 1 percentage point. There are two possible reasons for this difference. First, they use time series variation in the mortgage rate, whereas I use cross-sectional variation, which has a standard deviation in the mortgage rate about twice as much as theirs. Second, their data are annual, whereas the PSID survey is biennial. Admittedly, lower frequency data may underestimate the borrowing propensity. For example, a household may take a second mortgage and repay within two years. However, their dataset does not contain the detailed information about household expenditures needed to answer questions posed in my paper. My estimates also differ from those in Wong (2015) in that she estimates the propensity of refinancing, which includes both cash-out and interest-rate refinancing, whereas I focus on all forms of mortgage borrowing, including cash-out refinancing, second mortgages, HELOCs, and new, larger loans.
} 
individual-level heterogeneity that correlates with borrowing decisions. I address this concern by performing two robustness checks (the results of which are not shown to conserve space). First, I control for the previous-period LTV ratio as a proxy for the risk of the borrower. Second, I estimate a panel logit model that includes individual fixed effects. The estimated effect of a mortgage rate reduction and the heterogeneity of this effect across age are robust to these changes.

\section{Model}

In this section, I describe a heterogeneous-agent life-cycle model designed to be consistent with the empirical facts documented in Section 2. The model has two consumption goods: non-housing consumption and housing services. Households face uninsured labor income risks. There are three ways to save: increasing liquid assets, paying down mortgage debt, and investing in housing. Households are allowed to use their houses as collateral to borrow, but borrowing cannot exceed the value of the house. In addition, households have to pay an adjustment cost to change their mortgage debt above or below the predetermined level.

The model is adapted from Berger et al. (2015, 2017). There are three key differences. First, whereas Berger et al. build a theoretical model of consumption and study the response of consumption to house price shocks, the current paper emphasizes the responses of both consumption and residential investment to a wider range of shocks. Second, I investigate whether this type of model can simultaneously explain the micro and macro evidence, including the large heterogeneity by household age and borrowing status. Third, my model differentiates between long-term mortgage debt and liquid savings by specifying fixed costs for adjusting mortgage debt and no cost for changing liquid savings. This separation allows homeowners to smooth their consumption using liquid savings without tapping their home equity. In addition, this separation allows for different interest rates on the two assets.

\subsection{Setup}

The economy is populated with overlapping generations of households whose income and assets differ across the life cycle. The model frequency is annual. In each year a mass of households is born and lives for $J$ periods. In the first $J_{y}$ periods of life, households work and earn labor income. In the remaining $J-J_{y}$ periods, households retire and receive a fixed income each period. Households are endowed with an initial housing stock, a pre-existing mortgage balance, and an initial amount of liquid assets. In each period of the life cycle, households make decisions on consumption and housing investment expenditures, liquid savings, and whether and how much to 
change their mortgage borrowing. Households leave their total wealth at the end of their life as a bequest.

A household born in time $t$ maximizes expected lifetime utility

$$
E_{t}\left[\sum_{j=0}^{J-1} \beta^{j} u\left(c_{j, t+j}, h_{j, t+j}\right)+\beta^{J} \Phi\left(w_{J, t+J}\right)\right],
$$

where the first subscript of a variable denotes the household's age and the second subscript denotes time. $c$ and $h$ denote consumption and the housing stock, respectively. I assume that the flow services generated by the housing stock are proportional to the housing stock. The second term inside the expectation operator represents the discounted utility from leaving a bequest, specified by the bequest function $\Phi$ (see the functional form in Section 4 ). $w_{J, t+J}$ denotes the total wealth at the end of the household's life.

Events in any period of life occur in the following sequence: (1) income and the aggregate state are realized. (2) Liquid savings carried from the previous period earn returns. (3) Housing services provided by the predetermined housing stock are consumed. (4) The housing stock depreciates, and the collateral value is determined. (5) Homeowners decide whether to change their mortgage balance. If they do, they pay a mortgage adjustment cost, choose a new mortgage balance not exceeding the collateral value, and agree on a new repayment plan. If they do not, they repay according to the original mortgage plan as described below, and the balance evolves according to that plan. (6) Housing investment, consumption, and liquid savings are chosen.

I consider a fully amortized mortgage scheme where the loan is amortized over the remaining life of the borrower. ${ }^{21}$ This scheme implies that mortgages are long-term debt and that the loan-to-value requirement (or the collateral constraint) has to be satisfied only at mortgage origination. ${ }^{22}$ The periodic payment can be calculated based on a repayment formula, derived by assuming a constant payment in each period and a full repayment at the end of the term. Given the principal amount $b$, mortgage rate $r$, and contract term $T$, the per-period payment calculated using the formula is $M(b, r, T)=\frac{r b}{1-(1+r)^{-T}}$. Over the life of the loan, if the mortgage rate is constant, each periodic payment is the same. When the mortgage rate is changing, I allow an automatic change of the

\footnotetext{
${ }^{21}$ This assumption is made to reduce the dimension of the state space. An alternative amortization structure would be a constant-term schedule amortizing over 15 or 30 years, which would make the remaining terms of the mortgage loan an additional state variable.

${ }^{22}$ The presence of long-term debt implies that underwater homeowners are insensitive to changes in house prices (or mortgage debt relief) that do not affect their budget constraint (see Ganong and Noel (2017), Kaplan et al. (2017), and Berger et al. (2017)). This means that in a recession when house prices fall sharply, consumption falls less than under a short-term debt environment because lenders cannot force underwater homeowners to deleverage. A drop in the mortgage rate, in contrast, effectively stimulates consumption due to the immediate reduction in mortgage payments.
} 
periodic payment according to the prevailing mortgage rate. Therefore, borrowers pay mortgage adjustment costs only when they change their outstanding balance. The mortgage balance evolves when a borrower makes payment. Specifically, if a borrower of age $j$ at period $t$ with an initial balance $b_{j, t}$ chooses not to change the mortgage balance, he pays $M\left(b_{j, t}, r_{t}, J-j+1\right)$, and the mortgage balance at the beginning of $t+1$ is $\left(1+r_{t}\right) b_{j, t}-M\left(b_{j, t}, r_{t}, J-j+1\right)$.

\subsection{Household Problem}

At time $t$, the aggregate state is characterized by the house price $p_{t}$, the cost of housing investment $p_{t}^{I}$, and the mortgage rate $r_{t}^{b}$. Let $S_{t}$ denote the aggregate state, where $S_{t} \equiv\left(p_{t}, p_{t}^{I}, r_{t}^{b}\right)$. Household $i$ of age $j$ at time $t$, given his housing stock $h_{j, t}^{i}$, mortgage balance $b_{j, t}^{i}$, liquid savings $a_{j, t}^{i}$, income $y_{j, t}^{i}$, and the aggregate state $S_{t}$, chooses whether to change the current mortgage balance by comparing the value of changing, $V_{j, t}^{C}$, and not changing, $V_{j, t}^{N}$. I suppress the household subscript $i$ and the time subscript $t$ for notational simplicity in describing the household's problem. The higher value between the two options is $V_{j}(h, b, a, y ; S)=\max \left\{V_{j}^{C}(h, b, a, y ; S), V_{j}^{N}(h, b, a, y ; S)\right\}$.

If the household chooses to change its mortgage balance, the value function is given by

$$
\begin{aligned}
V_{j}^{C}(h, b, a, y ; S)=\max _{h^{\prime}, b^{\prime}, a^{\prime}, c} u(c, h) & +\beta E_{j}\left[V_{j+1}\left(h^{\prime}, b^{\prime}, a^{\prime}, y^{\prime} ; S^{\prime}\right)\right] \\
\text { s.t. } \quad c+a^{\prime}+p^{I}\left[h^{\prime}-h(1-\delta)\right] & =y+\left(1+r^{a}\right) a-\left(1+r^{b}\right) b+b^{\prime}-F \\
b^{\prime} & \leq \frac{(1-\theta)(1-\delta)}{1+r^{b}} p h \\
h^{\prime} & \geq(1-\delta) h \\
a^{\prime} & \geq 0 ; \quad b^{\prime} \geq 0,
\end{aligned}
$$

where $F$ denotes the loan adjustment cost, $\theta$ denotes the down payment rate, $\delta$ denotes the housing stock depreciation rate, and $r^{a}$ denotes the return on liquid savings.

The first line in the constraint set is the budget constraint, where $p^{I}\left[h^{\prime}-h(1-\delta)\right]$ is the housing investment expenditures at unit cost $p^{I}$. The second line is the collateral constraint which requires the amount of the loan to be below the collateral value. The latter is jointly determined by the house value $p h$, the down payment rate $\theta$, the depreciation rate $\delta$, and the mortgage rate $r^{b}$. The third line is the irreversible investment constraint that restricts households from actively downsizing their housing stock. ${ }^{23}$ An alternative interpretation of this constraint is that households

\footnotetext{
${ }^{23}$ There are two potential misunderstandings worth clarifying. First, this assumption does not imply that the home size of an individual and the aggregate housing stock never decline. Households can passively downsize their home by letting it depreciate, as would be the case for the old households in this model. Second, this assumption does not mean that households cannot trade their homes. It implies that when they sell the old home and buy a new one, they choose the size of the new home at least equal to the old size allowing for depreciation. In the PSID survey data, $80 \%$ of homeowners who sold their old home purchased a more expensive one. This share is almost $90 \%$ for
} 
pay an extremely large transaction cost when actively downsizing their homes. The rationale for including such a constraint is to capture the life-cycle housing consumption profile documented by Yang (2009), who shows that the housing consumption profile increases monotonically over the life cycle, before flattening out. She proposes that the main theoretical explanation for the flat portion is large transaction costs on downsizing the home. Without this constraint, households in the model would downsize their home before retirement in order to repay the mortgage and to finance retirement consumption. This implies a sharply declining housing stock toward the end of the life cycle, which is inconsistent with the data. The last line in the constraint set requires both liquid savings and mortgage balances to be non-negative.

If the household chooses not to change its mortgage balance, the value function is given by

$$
\begin{aligned}
V_{j}^{N}(h, b, a, y ; S)=\max _{h^{\prime}, a^{\prime}, c} u(c, h) & +\beta E_{j}\left[V_{j+1}\left(h^{\prime}, b^{\prime}, a^{\prime}, y^{\prime} ; S^{\prime}\right)\right] \\
\text { s.t. } \quad c+a^{\prime}+p^{I}\left[h^{\prime}-h(1-\delta)\right] & =y+\left(1+r^{a}\right) a-M \\
b^{\prime} & =\left(1+r^{b}\right) b-M \\
h^{\prime} & \geq(1-\delta) h ; \quad a^{\prime} \geq 0,
\end{aligned}
$$

where $M \equiv M\left(b, r^{b}, J-j+1\right)$ is the periodic payment calculated from the repayment formula. When the household chooses not to adjust its borrowing, the mortgage balance $b^{\prime}$ taken to the next period is determined by the second line in the constraint set. Note that homeowners can invest in their housing even without adjusting their mortgage. However, even if homeowners are given this option, Section 5.2 will show that they tend to delay housing investment to the time when they adjust their mortgage. Such behavior reflects the presence of mortgage adjustment costs, which effectively play the role of adjustment costs to the housing stock.

Households face income uncertainty during their working life. The logarithm of the income process is specified as

$$
\log \left(y_{j, t}^{i}\right)=\chi_{j}+z_{j, t}^{i}
$$

where $\chi_{j}$ is an age-specific deterministic component, same for all households of age $j . z_{j, t}^{i}$ is the idiosyncratic shock to income, which evolves according to

$$
z_{j, t}^{i}=\left(1-\rho_{z}\right) \bar{z}+\rho_{z} z_{j-1, t-1}^{i}+\varepsilon_{j, t}^{i} \quad \varepsilon_{j, t}^{i} \sim^{i . i . d .}\left(0, \sigma_{e z}^{2}\right)
$$

where $\bar{z}$ is the unconditional mean of $z, \rho_{z}$ is the persistence parameter, and $\varepsilon_{j, t}^{i}$ is a mean zero i.i.d. shock with variance $\sigma_{e z}^{2}$. Households have rational expectations toward the change in their

homeowners aged 26-35. 
income. Given $z_{j, t}^{i}, z_{j+1, t+1}^{i}$ is normally distributed with a conditional mean of $\left(1-\rho_{z}\right) \bar{z}+\rho_{z} z_{j, t}^{i}$ and a conditional variance of $\sigma_{e z}^{2}$.

\subsection{Solution Methods}

The model is solved numerically by backward induction using a two-step procedure. In the first step, I discretize the state space and then solve the value functions over fixed grids of the states. In the second step, I obtain the policy functions by solving the optimization problem over finer grids, given the value functions obtained in the first step. The numerical procedure is described in detail in Appendix B.

\section{Calibration}

In order to assess the quantitative implications of the model, I calibrate the model parameters. A summary of the parameter values can be found in Table 10 . Age is indexed by $j=0, \ldots, J-1$. Households enter the life cycle at age 26, work for 40 years, retire at the end of age 65 and live another 20 years in retirement, so $J=60$ and $J y=40$. The initial home size, mortgage balance, and total wealth are set to match the mean of their counterpart in the PSID for households aged 21-25.

The utility function is of Cobb-Douglas form, $u(c, h)=\left(c^{\alpha} h^{1-\alpha}\right)^{1-\sigma} /(1-\sigma)$, where $\sigma$ denotes the inverse of the inter-temporal elasticity of substitution, and $\alpha$ denotes the expenditure share of consumption. Following standard conventions in the consumption literature, I set $\sigma=2$. I set $\alpha=0.81$ to match the distribution of housing investment expenditures across age bins in the model and in the PSID data (see Figure 3, housing investment panel). I set the discount factor $\beta=0.935$ to match the distribution of the wealth to income ratio across age bins in the model and in the PSID data (see Figure 3, wealth panel).

Households leave their total wealth at the end of their life as a bequest. The bequest function is specified as $\Phi(w)=\eta w^{1-\sigma} /(1-\sigma)$, where $w \equiv\left(1+r^{a}\right) a-\left(1+r^{b}\right) b+p^{I} h(1-\delta)$ denotes total wealth. $\eta$ is the bequest parameter. I set $\eta=6$. This parameter affects borrowing and investment decisions in the last few years of the life cycle. For small $\eta$, the model generates a large borrowing propensity toward the end of the life cycle. This is because, as impatient households deplete all their liquid savings, they finance retirement consumption by increasing their mortgage debt. Since there is no such spike in the data, I choose a large $\eta$ such that the borrowing propensity remains roughly constant during retirement.

I use the PSID data to estimate both the deterministic and the idiosyncratic component of the 
income process specified in equations (8) and (9). To obtain the deterministic component, $\chi_{j}, \mathrm{I}$ regress the log of deflated annual household income on the first and second order polynomial of the household head's age. I then normalize the fitted age profile by subtracting the fitted value of the age 26 households, so that the permanent income at age 26 is 1 . To estimate the distribution of the stochastic component, $z_{j, t}^{i}$, I calibrate $\rho_{z}$ and $\sigma_{e z}$ by taking the residual from the $\chi_{j}$ regression described above and estimating an $\operatorname{AR}(1)$ process. ${ }^{24}$ The estimates are $\rho_{z}=0.9$ and $\sigma_{e z}=0.18$. I assume that, in the stationary equilibrium, the average income path of a cohort over its life cycle is equal to the deterministic income path, i.e., $E y_{j}^{i}=\exp \left(\chi_{j}\right)$, which implies $E\left[\exp \left(z_{j}^{i}\right)\right]=1$. Therefore $\bar{z}=-\frac{\sigma_{z}^{2}}{2}$, assuming $z_{j}^{i}$ is normally distributed, where $\sigma_{z}^{2}$ is the variance of $z_{j}^{i}$. I assume a fixed annual income structure during retirement. Every year, retirees receive a constant amount that is a $\zeta$ fraction of the permanent income in the last working age. In the PSID data, the annual income of households aged 66 and above is about $60 \%$ of households aged $61-65$, so I set $\zeta=0.6$.

The housing depreciation rate is set to $\delta=0.0227$, following the depreciation rate of residential 1- to 4-unit structures, as published by the Bureau of Economic Analysis (BEA). The down payment rate, $\theta$, is set to $25 \%$. The fixed cost of the mortgage adjustment is set to $F=0.025$. This number is derived from the information in A Consumer's Guide to Mortgage Refinancings, published by the Federal Reserve Board in 2008, which shows that the closing costs of refinancing a mortgage are about 2 to $6 \%$ of the outstanding principal. Using the average outstanding principal and income reported in the PSID, I infer that fixed costs represent between 2.5 and $7.7 \%$ of households' income. I choose the lower end of this range for my calibration. The steady state house price, $p$, and the cost of housing investment, $p^{I}$, are normalized to 1 . The steady state mortgage rate $r^{b}$ is set equal to 0.04 , based on the historical average of the 30-year fixed mortgage rate net of inflation during 1990-2015. The return on liquid assets, $r^{a}$, is set to 0.01 .

Although some moments in the data (such as the distribution of income and wealth) are used to calibrate the model, other moments that are key to understanding homeowners' choices are not targeted. In the next three sections, I evaluate the performance of the calibrated model along four dimensions: (1) untargeted moments such as the life-cycle profiles of consumption and housing investment; (2) household-level spending patterns estimated by regression models in Section 2.2; (3) responses of homeowners' borrowing to housing market shocks; and (4) the boom-bust cycles

\footnotetext{
${ }^{24}$ Since the PSID is a biennial survey, the annual income is reported every other year, so I cannot estimate equation (9) directly. Iterating equation (9) by one period, we have $z_{j, t}^{i}=\left(1+\rho_{z}\right)\left(1-\rho_{z}\right)+\rho_{z}^{2} z_{j-2, t-2}^{i}+\left(\varepsilon_{j, t}^{i}+\rho_{z} \varepsilon_{j-1, t-1}^{i}\right)$. This allows me to estimate an $\operatorname{AR}(1)$ process using $z_{j, t}^{i}$ and $z_{j-2, t-2}^{i}$, and to recover the original parameters, $\rho_{z}$ and $\sigma_{e z}$.
} 
in aggregate consumption and residential investment.

\section{Can the Model Capture the Micro-Level Evidence?}

This section characterizes the stationary equilibrium by simulating the optimal life-cycle choices of 216,000 households, corresponding to 3,600 households in each cohort. I then compare the age profiles of these choices with the PSID data. First, I show that the life-cycle profiles (suitably averaged across households in the same age group) based on the simulated data match those in the household survey data. Second, I show that the model captures the heterogeneity in household spending across households' age and their borrowing status, as documented in Section 2.2. The model helps interpret the strong correlation between increased mortgage debt and housing investment expenditures.

\subsection{Average Life-Cycle Profiles}

Figure 3 plots life-cycle profiles averaged across households in the same age group for income, total wealth, liquid savings, housing investment expenditures, and consumption. I compare the simulated data based on the calibrated model to the survey data. The income of the youngest age group, 26-30, is normalized to 1 . Total wealth and liquid savings are expressed in proportion to the income of the youngest age group. Housing investment and consumption expenditures are normalized by the corresponding expenditures of the youngest age group. I focus on outcomes over the working life of households because the standard life-cycle model is not designed to capture the risks faced by retirees. ${ }^{25}$

The empirical life-cycle profiles are constructed based on PSID data and CE data along the same lines as for the simulated data. The total wealth and liquid savings are taken from the PSID, deflated by the CPI, then averaged across households from all years by age group. The age profiles of housing investment and consumption expenditures are constructed similarly. The housing investment expenditures are defined as in Section 2.2, including investment through trading homes, expenditures on home improvements, remodeling, and additions, and investment on a second home or real estate. The consumption expenditures are defined as in Section 2.2, excluding mortgage payments. One concern is that the PSID survey may not capture the full scope of

\footnotetext{
${ }^{25}$ The model implies that, after retirement, total wealth and liquid savings decrease monotonically. This happens because income is low relative to the working age, and impatient households deplete their savings to finance retirement consumption. In addition, since there is no uncertainty after retirement, households do not have a precautionary saving motive. In the data, in contrast, retired households hold a substantial amount of wealth, both in liquid savings and in housing wealth. This fact may be explained by uncertainties faced by retirees that the standard life-cycle model abstracts from.
} 
personal consumption expenditures. I therefore also construct the age profile of the consumption expenditures from the CE data between 1994 and 2014, following the same sample selection criteria as in Section 2.1.

The calibrated model successfully captures the patterns in the survey data. Income follows a hump shape, and the model generates an increasing age profile of total wealth during the working age. This pattern is explained by the fact that households build up their housing wealth and accumulate liquid savings during the working age. In the model, there are two incentives to accumulate liquid savings: the precautionary saving motive due to income uncertainty, and the need to finance retirement consumption. Investment expenditures on housing decline with age, which implies that the average home size grows faster for young households. In the model, since young households start their life with a small house, the high marginal utility from enjoying housing services drives them to invest in their homes. The consumption path is hump-shaped. The rising part is due to binding liquidity constraints, and the declining part is explained by impatience. The hump-shaped pattern has also been empirically documented in Fernandez-Villaverde and Krueger (2006) and Yang (2009). Finally, both the model and data imply a decreasing borrowing propensity over the life cycle. However, the decline in the model is faster than in the data. Whereas in the data, the borrowing propensity declines from $15 \%$ at age $26-30$ to $8 \%$ at age $61-65$, in the model it declines from $14 \%$ at age $26-30$ to $3 \%$ at age $61-65$.

\subsection{Household-Level Spending Patterns}

Section 5.1 shows that the calibrated model successfully captures the average life-cycle profiles of wealth, consumption, and borrowing. However, life-cycle profiles averaged across all households mask the heterogeneity at the household level. For example, in the data, homeowners who increase their mortgage debt use the borrowed funds primarily to finance housing investment expenditures, and this tendency is particularly strong among young homeowners. There has not been an effort to examine the ability of the life-cycle model to capture these patterns. I address this question by performing the same regression analysis as in Section 2.2 on simulated data from the model in the stationary equilibrium. This exercise directly evaluates the ability of the model to capture a richer set of empirical facts. The model also serves to rationalize the observed spending behavior.

First, I examine whether the model implies that homeowners who increase their mortgage debt tend to spend on housing investment. I estimate the logit model as specified in equation (1) with two differences. First, since the model does not distinguish between different types of 
housing investment, I define the event of making a housing investment as a household spending more than $2 \%$ of its income on enlarging the home size. ${ }^{26}$ Second, since this exercise characterizes the stationary equilibrium, I do not include year dummies. The regression model using simulated data is

$$
P\left(\text { Invest }_{i, j}=1\right)=\alpha_{0}+\alpha_{1} \text { Extract }_{i, j}+X_{i, j} \alpha_{2}+W_{i, j-1} \alpha_{3}+\alpha_{4} \triangle y_{i, j}+\varepsilon_{i, j},
$$

where subscript $i$ denotes household and $j$ denotes age. Invest $t_{i, j}$ is the indicator of whether household $i$ spends more than $2 \%$ of its income on housing investment at age $j$. Extract $t_{i, j}$ is the indicator of whether household $i$ increases its mortgage debt at age $j . X_{i, j}$ includes household $i$ 's age and age-squared. $W_{i, j-1}$ includes lagged income, lagged liquid savings, and lagged illiquid wealth (total wealth minus liquid savings). $\triangle y_{i, j}$ denotes the growth rate of income of household $i$ from age $j-1$ to $j$.

The model implies that increased mortgage debt is associated with investment in housing (see Table 11). On average, homeowners who increase their mortgage debt are $13 \%$ more likely to spend on housing than other homeowners. This propensity is largest among young households, and monotonically decreases with age. These results are consistent with the empirical counterpart in panel (I) of Table 2. For the last age group, the model implies that the propensity to invest in housing of those who borrow more is much lower than of those who do not borrow more. One reason is that the home size is already large at that age, so the value of extra housing services diminishes. Another reason is that old households who borrow more are those suffering from bad income shocks and low liquidity. They borrow primarily to smooth their consumption.

Second, I estimate the difference in expenditure growth between those who increase their mortgage debt and those who do not. The specification is similar to (2) but does not include year dummies. I examine the growth of consumption, housing investment, and total expenditures (the sum of consumption and housing investment). I normalize the growth of consumption and housing investment by total expenditures in the previous period. The linear regression model using simulated data is

$$
\frac{\triangle \text { Expenditures }_{i, j}^{k}}{\text { TotalExpenditures }_{i, j-1}}=\beta_{0}^{k}+\beta_{1}^{k} \text { Extract }_{i, j}+X_{i, j} \beta_{2}^{k}+W_{i, j-1} \beta_{3}^{k}+\beta_{4}^{k} \triangle y_{i, j}+\varepsilon_{i, j}^{k},
$$

where $\triangle$ Expenditures $_{i, j}^{k}$ denotes the change in expenditures on consumption or housing. Other variables are defined as in equation $\left(1^{\prime}\right)$.

\footnotetext{
${ }^{26}$ The results are similar to alternative income thresholds. In fact, setting a higher income threshold produces a larger correlation between borrowing and housing investment among young homeowners, because young homeowners make most housing investments.
} 
Table 12 shows that the growth rate of total expenditures of those who increase their mortgage debt is 14 percentage points higher than that of those who do not, consistent with Table 3 . The difference in housing investment growth accounts for almost all of the differences in total expenditure growth between the two groups. The difference in consumption growth in Table 12 is only 2 percentage points, and there is no discernible age pattern for this difference. Table 12 also shows the difference in housing investment growth between the two groups by age. Clearly, the difference in housing investment growth is shrinking with age, consistent with the empirical findings in Table 4.

Third, I estimate the change in consumption and housing investment expenditures for a one-dollar increase in mortgage debt, analogous to equation (3) but without year dummies. The regression model is

$$
\triangle \text { Expenditures }_{i, j}^{k}=\delta_{0}^{k}+\delta_{1}^{k} \triangle b_{i, j}+X_{i, j} \delta_{2}^{k}+W_{i, j-1} \delta_{3}^{k}+\delta_{4}^{k} \triangle y_{i, j}+u_{i, j}^{k} .
$$

All variables have the same definitions as in equation $\left(2^{\prime}\right)$. Table 13 shows the estimates of equation $\left(3^{\prime}\right)$ based on the simulated data. For a one-dollar increase in mortgage debt, 51 cents are spent. The increase in housing investment expenditures accounts for 45 cents. The increase in consumption of 6 cents is small, and there is no discernible age pattern for this change. The age decomposition in Table 13 shows that young homeowners spend most of the borrowed funds on housing investment. Again, these results are quantitatively consistent with their empirical counterpart in Table $6 .{ }^{27}$

Thus, not only does the model generate borrowing and spending patterns similar to the survey data, but it also helps to interpret the strong tendency of using mortgage debt to finance housing investment expenditures. This correlation arises due to the life-cycle features of the model. In the stationary equilibrium, young households start their life with small homes. This implies that the marginal utility of housing consumption is high and that they want to invest in housing. Since young homeowners are liquidity constrained, they must use their home as collateral to finance the investment. In the absence of mortgage adjustment costs, housing investment would be made continuously as homeowners increase their mortgage debt, until the home size reaches the desired level. Mortgage adjustment costs, however, prevent homeowners from raising their debt continuously. As a result, housing investment becomes lumpy, and homeowners delay investing until they can borrow a large amount of cash. This explains why, in the data, homeowners who

\footnotetext{
${ }^{27}$ The model data show that the remaining borrowed funds mostly enter liquid savings, with a small fraction being used for mortgage payments. This result is consistent with the insight in Kaplan and Violante (2014) that households store some borrowed funds as liquid savings for future spending. This behavior is due to the fact that cashing out illiquid assets is costly and that households need buffer savings to smooth their consumption.
} 
increase their mortgage debt tend to spend largely on housing investment.

\section{Can the Model Capture the Responses to Shocks in the Housing Market?}

The calibrated model may also be used to quantify the impact of two shocks in the housing market: a positive house price shock and a reduction in the mortgage rate. I focus on permanent shocks because the time series data for real house prices and real mortgage rates are highly persistent. For each shock, I analyze the response of the propensity to borrow, the response of consumption, and the response of housing investment. The first response can be compared with the empirical estimates in Section 2.3, allowing me to evaluate the fit of the model along another dimension. The latter two responses quantify the effect of these shocks on aggregate expenditures through the collateral channel, which is hard to identify empirically.

\subsection{House Price Shocks}

Earlier studies that used structural models to compute the responses of consumption to house price shocks considered the thought experiment of simultaneously shocking the house price, $p$, and the cost of housing investment, $p^{I}$ (see, e.g., Chen et al. (2013) and Berger et al. (2015, 2017)). This experiment assumes that shocks to house prices are passed through completely to the cost of housing investment. This need not be the case. For example, the cost of home improvements largely depends on the cost of the structures, not of the land (see, e.g., Davis and Heathcote (2007)).

In this section, I compute the responses to a positive shock to the house price, $p$, assuming the cost of housing investment $p^{I}$ is unchanged. This experiment helps to isolate the collateral effect from the effects brought by a change in the relative price between housing and consumption. Figure 4 shows the impact responses of the borrowing propensity, consumption, and housing investment expenditures to a $1 \%$ unexpected permanent increase in the house price. A higher house price increases the collateral value, relaxes the collateral constraint, and stimulates borrowing. The left panel shows that a $1 \%$ increase in the house price causes a 0.54 percentage-point increase in the borrowing propensity on average. This response is largest among young homeowners and monotonically declines with age, consistent with the regression evidence in Section 2.3.

Both consumption and housing investment expenditures increase on average. The elasticity of consumption with respect to the house price is 0.05 overall, with large heterogeneity across households. For example, the elasticity for the youngest homeowners is 0.12 ; it is almost zero for those older than 55. The elasticity of housing investment is much larger (1.22 on average) and exceeds 3 for the youngest households. Figure 5 decomposes the responses of consumption and 
housing investment between those who increase their mortgage balance (extractors) and those who do not (nonextractors). It shows that almost all of the effect of higher house prices is driven by those who increase their borrowing, especially the young borrowers. ${ }^{28}$

\subsection{Mortgage Rate Shocks}

Recent empirical and theoretical studies have stressed the importance of the housing market in transmitting monetary policy shocks to consumption (see, e.g., Aladangady (2014), Bhutta and Keys (2016), Beraja et al. (2015), and Wong (2015)). One channel through which monetary policy shocks can affect consumption is a change in the mortgage rate. The effect of a changing mortgage rate on household borrowing and spending, however, depends on the type of the mortgage instrument, as noted by Campbell and Cocco (2003).

In the U.S. market, the typical residential mortgage instruments are fixed-rate mortgages (FRM, 15-year, 20-year, and 30-year) and adjustable-rate mortgages (ARM, terms depend on the initial interest rate period and the adjustment period). The variety of mortgage instruments and borrowers' selection between these products makes it challenging to model the U.S. mortgage market. ${ }^{29}$ In this section, I analyze the effects of a mortgage rate shock on the economy described in Section 3, which resembles the ARMs common in the early 2000s. This exercise sheds light on the extent to which a lower mortgage rate stimulates borrowing when adjusting the debt level is costly. Since a change in the mortgage rate affects all households, even those who do not change their borrowing amount, the aggregate consumption response is determined by all homeowners.

Figure 6 shows the impact responses of the borrowing propensity, consumption, and housing investment expenditures to a 1 percentage-point unexpected permanent reduction in the mortgage rate by age group. The borrowing propensity rises for all age groups. However, this response is not monotonically decreasing with age. It peaks at age group 36-45, consistent with the empirical age profile of this response. This is because a decline in the mortgage rate does not raise the collateral value immediately and hence makes little difference for young homeowners whose current debt is

\footnotetext{
${ }^{28}$ In Appendix C, I instead follow the existing literature in assuming complete pass-through of a positive house price shock to the cost of housing investment. In that case, a higher house price also implies that housing investment is more expensive. Therefore, households tend to substitute consumption for housing services. As a result, the consumption response to a positive house price shock is even larger than in this section, and the housing investment response becomes negative. However, the housing investment of those who increase their mortgage debt is still large and positive, especially among young homeowners.

${ }^{29}$ According to Wilson (2016), fixed-rate products accounted for $86 \%$ of the market between 2004 to 2014 , with the 30-year FRM being the most common type. However, the market composition has not been stable. Between 2004 and 2006, the share of 30-year FRMs was below 50\%, while the share of non-FRM products exceeded $26 \%$ and kept rising. After the financial crisis, the share of the 30-year FRM soared, while non-FRM products became less popular. By 2014, the 30-year FRM accounted for $71 \%$ of the market and non-FRMs only accounted for $7 \%$.
} 
almost at the collateral value. It is those aged 36-45 who have few liquid assets, but who have accumulated substantial home equity, who benefit the most from a mortgage rate reduction. In addition, a lower mortgage rate reduces mortgage payments for all borrowers. It provides liquidity even for those who do not adjust their debt level, which further lowers young homeowners' incentive to increase their borrowing. The response of consumption and housing investment expenditures follows the same pattern as the borrowing propensity.

Figure 7 decomposes the responses of consumption and housing investment into those who increase their borrowing (extractors) and those who do not (nonextractors). The age profile of the response of consumption and housing investment of extractors follows a hump shape similar to that of the borrowing propensity. Among all extractors, middle-aged extractors have the largest response in their spending. Note that even homeowners who do not change their borrowing amount respond to the mortgage rate reduction. This is because a lower mortgage rate reduces mortgage payments for all homeowners, and hence creates a wealth effect. The consumption panel shows that young extractors drive the consumption response among young homeowners, whereas non-extractors drive the consumption increase among old homeowners. A similar pattern is observed in the housing investment panel.

\section{Can the Model Capture the Boom-Bust Cycles in the 2000s?}

In this section, I examine to what extent the heterogeneous-agent life-cycle model of Section 3 can capture fluctuations in aggregate consumption and residential investment. For this purpose, I feed U.S. historical time series data on real house prices, the real price of residential structures, and real mortgage rates into the model. Given that the model has been calibrated based on micro data, there is no presumption that the model matches the aggregate data. I show that the model, nevertheless, captures key features of the boom-bust cycle in the U.S. data between 2000 and 2010. I then use the model to conduct two counterfactual analyses to quantify the role of the collateral channel in transmitting aggregate shocks during this period.

\subsection{Simulated and Actual Aggregate Data}

The upper panel of Figure 8 shows the three U.S. time series fed into the model (for a detailed data description, see Appendix A). The house price series, $p_{t}$, is the Case-Shiller U.S. National

Home Price Index, deflated by the CPI. The cost of home investment, $p_{t}^{I}$, is proxied by the price index for residential structures, deflated by the CPI. The mortgage rate, $r_{t}^{b}$, is the 30-year fixed mortgage rate adjusted for the CPI inflation, except for the year 2009. In 2009, the CPI inflation 
rate fell sharply to $-0.32 \%$ from $3.81 \%$ in 2008 , and then quickly bounced back to $1.64 \%$ in 2010 . This was due to a sharp increase in oil prices in 2008 and its subsequent fall in 2009. Since short-lived oil price shocks are less likely to be passed through to the real mortgage rate, I replace the CPI inflation rate in 2009 with the inflation rate calculated based on the CPI excluding food and energy.

In the baseline simulation, I assume that households take the path of future house prices as deterministically given. In other words, after a house price shock, households expect future house price levels equal to the current house price level. Analogous assumptions are made with respect to the mortgage rate and the cost of home investment. In Appendix D, I implement an alternative expectations assumption, according to which households expect that future house prices and investment costs continue to grow at the current rate. The fit of the model is robust to this change in assumptions.

The lower panel of Figure 8 shows the evolution of consumption, residential investment and the debt-to-income ratio between 2000 and 2015 simulated based on the calibrated model. Consumption and residential investment are converted to percent deviations from their value in 2000 . The model generates a boom-bust cycle for both consumption and residential investment in the 2000s. It also sheds light on what caused the boom-bust cycle during this period. Between 2000 and 2005, house prices increased sharply, the cost of housing investment increased moderately, and the mortgage rate fell from $5 \%$ to $2 \%$. These developments stimulated homeowners to increase their mortgage debt. As analyzed earlier, borrowers, especially young homeowners, spent these funds largely on housing investment. The aggregate housing stock was built up, facilitating more borrowing, which in turn financed further spending on housing investment and consumption. In the subsequent five years, as house prices fell sharply and the mortgage rate increased, fewer households were able to borrow. As a result, housing investment declined, collateral value shrank, and consumption slumped. In 2011, as the mortgage rate dropped, both consumption and residential investment spiked. After 2011, as the mortgage rate kept rising, consumption and residential investment declined, even as house prices recovered.

In Figure 9, I evaluate the model's ability to explain the U.S. data by comparing the simulated data with the corresponding U.S. data. I focus on the period of 2000 to 2010 because after the financial crisis, various government actions were taken, on the one hand to regulate credit markets, and on the other hand to stimulate the housing market. These policies introduced mechanisms and 
shocks that are not captured by the model. ${ }^{30}$ Moreover, borrowers increasingly relied on fixed-rate mortgages. This shift as well is beyond the scope of the model.

Since the model abstracts from trend growth in income, the U.S. data must be detrended. Figure 9 shows log-linearly detrended NIPA data for real personal consumption expenditures and residential investment during this period. Although the model is not intended to explain the entire business cycle, it replicates key features of the U.S. data. Notably, it captures the boom in consumption and residential investment before 2006, and the bust after 2007. The magnitude of the fluctuations is also comparable to the data. ${ }^{31}$

\subsection{Policy Experiments: The Role of the Housing Collateral Channel}

A central question since the financial crisis has been how important the housing collateral channel is for explaining the fluctuations in consumption in the 2000s. Answering this question empirically is not easy because of the difficulty of constructing a counterfactual. Given the ability of the calibrated model to match both the micro and macro evidence, I use this model to conduct two counterfactual analyses that shed light on the role of the housing collateral channel in transmitting aggregate shocks to consumption. In the first experiment, I shut off the home equity-based borrowing channel completely by removing the choice of using one's home as collateral. In the second experiment, I fix the mortgage rate at its value in the year 2000. I assess the counterfactual outcomes based on the standard deviations of the growth rate of consumption and residential investment between 2000 and 2010. I compare this volatility measure with the corresponding statistics based on the model.

In the first experiment, I consider a standard two-goods incomplete markets model, in which housing investment is still attractive because of the utility gains from enjoying housing services. However, a house does not have any collateral value. This means that both consumption and housing investment expenditures must be financed by liquid savings. The empirical counterpart of

\footnotetext{
${ }^{30}$ For example, the Dodd-Frank Wall Street Reform and Consumer Protection, passed by the Obama administration in 2010, was intended to decrease various risks in the U.S. financial system. Stimulative programs include the Home Affordable Modification Program (HAMP), designed to help financially struggling homeowners avoid foreclosure by modifying their loans, and the Home Affordable Refinance Program (HARP), which help homeowners, who otherwise would not qualify, to refinance. In addition, a recent study by Kermani et al. (2016) shows that QE2 (started in September 2010) and the subsequent QE3 have different effects on mortgage refinancing from QE1 (started in late 2008).

${ }^{31} \mathrm{~A}$ noticeable divergence between the model and the data occurs in 2006 and 2007 . Figure 9 shows that consumption was still rising, whereas the model predicts a decline. The reason why consumption in the model declines in 2006 and 2007 is that the mortgage rate fed into the model increased. The observed rise in U.S. consumption in 2006 and 2007 thus must be explained by other shocks such as income growth, an expansion of consumer credit, or rising foreign demand.
} 
such housing markets may be represented by most Asian countries that are either conservative in lending or do not have a well-developed mortgage market. Households under this counterfactual solve the problem

$$
\begin{gathered}
V_{j}(h, a, y ; S)=\max _{h^{\prime}, a^{\prime}, c} u(c, h)+\beta E_{j}\left[V_{j+1}\left(h^{\prime}, a^{\prime}, y^{\prime} ; S^{\prime}\right)\right] \\
\text { s.t. } \quad c+a^{\prime}+p^{I}\left[h^{\prime}-h(1-\delta)\right]=y+\left(1+r^{a}\right) a \\
h^{\prime} \geq(1-\delta) h ; \quad a^{\prime} \geq 0,
\end{gathered}
$$

where all notations have the same meaning as in the model of Section 3. Note that in this economy, shocks to the aggregate state, $S$, are solely represented by the changes in $p^{I}$. I calibrate this counterfactual using the same model parameters and the data on the real price index for residential structures.

The left panel of Figure 10 shows consumption in the counterfactual and in the original model. The volatility of consumption is much smaller under the counterfactual. Consumption increases slightly before 2006 and then falls, as does $p^{I}$. This is because an increase in $p^{I}$ drives households to substitute consumption for housing services. Since $p^{I}$ moves only moderately during the cycle, consumption under this counterfactual has almost no variation. The volatility of consumption under this counterfactual is only $11.4 \%$ of that in the original model. This means that the presence of the collateral channel accounts for almost $90 \%$ of the volatility in consumption during this period. For residential investment, the collateral channel explains $87 \%$ of the volatility.

In the second experiment, I fix the mortgage rate to its value at the beginning of the cycle in the year 2000, and calibrate the model with the same parameters, and historical data for real house prices and home investment costs. I evaluate the extent to which changes in the mortgage rate, resulting from monetary policy shifts and changes in lending conditions, contributed to fluctuations in consumption through the collateral channel.

The right panel of Figure 10 shows that between 2003 and 2005, the real mortgage rate had the effect of driving consumption up, and, in the following two years, it caused a decline in consumption. The evolution in the mortgage rate between 2000 and 2010 explains about $75 \%$ of the fluctuations in consumption and almost $90 \%$ of the variability in residential investment. This experiment shows that changes in the mortgage rate can have a large effect on consumption through the collateral channel. 


\section{Conclusion}

Some researchers have interpreted the empirical work of Mian and Sufi (2011, 2014) and Mian et al. (2013) as establishing that the U.S. aggregate consumption boom between 2000 and 2007 was largely driven by existing homeowners aggressively increasing their mortgage debt in an effort to finance additional consumption. As a result, recent quantitative models have focused on the role of the mortgage-borrowing channel in explaining the response of aggregate consumption to house price and interest rate shocks. I presented evidence that this conventional approach is inconsistent with micro evidence. Although rising house prices and low mortgage rates indeed stimulated home equity-based borrowing in the 2000s, as shown by Mian and Sufi (2011), household survey data show that most of the borrowed funds were spent on housing investment rather than consumption. This evidence is robust across time, across different data sources, and even across countries, raising the question of how to reconcile the boom-bust cycle in aggregate consumption with the low propensity to consume out of borrowed funds.

My analysis highlighted that increased borrowing can stimulate consumption through two distinct channels. One is an extensive margin: consumption increases because total borrowing increases. The other is an intensive margin: consumption increases because borrowers spend much of the borrowed funds on consumption. The micro-level evidence provided in this paper rules out the intensive margin channel emphasized by the conventional view. Thus, it is clear that the consumption boom-bust cycle must be mainly explained by an increase in the number of home equity borrowers and in total borrowing. The question is whether the apparent large variation in the extensive margin is a rational response to the variation in real house prices and mortgage rates.

I showed that the behavior of households during the consumption boom-bust cycle can be explained based on a two-goods, multiple-assets, heterogeneous-agent life-cycle model with borrowing frictions and collateral constraints. The model also captures the heterogeneity in household behavior across age groups found in the micro data. It not only captures the age profiles in steady state, but is also consistent with the estimated responses to house price and mortgage rate shocks, and it replicates key features of the evolution of aggregate consumption and residential investment.

The fact that homeowners spend their borrowed funds on housing investment is not only important for understanding what actually happened in the 2000s. It is also important because the consumption response to aggregate shocks changes with the endogenous distribution of the housing 
stock and of the mortgage debt (see Berger et al. (2017)). Studies that focus on the intensive margin alone fail to capture this state dependency in the consumption responses.

Given the ability of the model to capture both the micro and macro evidence, I use the model to conduct two policy experiments to quantify the role of the housing collateral channel in transmitting aggregate shocks. The first experiment shows that if houses were not collateral assets, the volatility of consumption between 2000 and 2010 would have been reduced by $90 \%$. The second experiment shows that if the mortgage rate had stayed the same as in the year 2000, consumption volatility between 2000 and 2010 would have been lower by 75\%. These experiments illustrate that the collateral channel was quantitatively important during the most recent consumption boom-bust cycle, even though borrowing affected consumption mostly through the extensive margin.

\section{References}

Aladangady, A., "Homeowner Balance Sheets and Monetary Policy," FRB Finance and Economics Discussion Paper 2014-98, 2014.

Andreski, P., G. Li, M. Z. Samancioglu and R. Schoeni, "Estimates of Annual Consumption Expenditures and Its Major Components in the PSID in Comparison to the CE," American Economic Review Papers and Proceedings 104 (2014), 132-135.

Benito, A. And J. Power, "Housing Equity and Consumption: Insights from the Survey of English Housing," Bank of England Quarterly Bulletin (2004), 302-309.

Beraja, M., A. Fuster, E. Hurst and J. Vavra, "Regional Heterogeneity and Monetary Policy," FRB Staff Report No. 731, 2015.

Berger, D., V. Guerrieri, G. Lorenzoni and J. Vavra, "House Prices and Consumer Spending," NBER Working Paper No. 21667, 2015.

__ , "House Prices and Consumer Spending," Review of Economic Studies, forthcoming (2017).

Bhutta, N. And B. Keys, "Interest Rates and Equity Extraction during the Housing Boom," American Economic Review 106 (2016), 1742-1774.

Brady, P., G. Canner and D. Maki, "The Effects of Recent Mortgage Refinancing," Federal Reserve Bulletin (2000), 441-450.

Campbell, J. and J. Cocco, "Household Risk Management and Optimal Mortgage Choice," Quarterly Journal of Economics 118 (2003), 1449-1494.

Canner, G., K. Dynan and W. Passmore, "Mortgage Refinancing in 2001 and Early 2002," Federal Reserve Bulletin (2002), 469-481.

Chen, H., M. Michaux And N. Roussanov, "Houses as ATMs? Mortgage Refinancing and Macroeconomic Uncertainty," NBER Working Paper No. 19421, 2013.

Cooper, D., "Did Easy Credit Lead to Overspending? Home Equity Borrowing and Household Behavior in the Early 2000s," FRB Boston Public Policy Discussion Paper, No. 2009-7, 2009. 
Davis, M. And J. Heathcote, "The Price and Quantity of Residential Land in the United States," Journal of Monetary Economics, 54 (2007), 2595-2620.

Fernandez-Villaverde, J. and D. Krueger, "Consumption over the Life Cycle: Facts from Consumer Expenditure Survey Data," Review of Economics and Statistics 89 (2006), 552-565.

Ganong, P. And P. Noel, "The Effect of Debt on Default and Consumption: Evidence from Housing Policy in the Great Recession," Unpublished, 2017.

Greenspan, A. and J. Kennedy, "Sources and Uses of Equity Extracted from Homes," Oxford Review of Economic Policy 24 (2007), 120-144.

Hurst, E. And F. Stafford, "Home Is Where the Equity Is: Mortgage Refinancing and Household Consumption," Journal of Money, Credit and Banking 36 (2004), 985-1014.

Iacoviello, M., "House Prices, Borrowing Constraints and Monetary Policy in the Business Cycle," American Economic Review 95 (2005), 739-764.

Iacoviello, M. And M. Pavan, "Housing and Debt over the Life Cycle and over the Business Cycle," Journal of Monetary Economics 60 (2013), 221-238.

Juster, T., J. Smith And F. Stafford, "The Measurement and Structure of Household Wealth," Labour Economics 6 (1999), 253-275.

Kaplan, G., K. Mitman and G. Violante, "The Housing Boom and Bust: Model Meets Evidence," NBER Working Paper No. 23649, 2017.

Kaplan, G. And G. Violante, "A Model of the Consumption Response to Fiscal Stimulus Payments," Econometrica 82 (2014), 1199-1239.

Kermani, A., M. D. Maggio and C. Palmer, "How Quantitative Easing Works: Evidence on the Refinancing Channel," NBER Working Paper No. 22638, 2016.

LI, G., "Transaction Costs and Consumption," Journal of Economic Dynamics and Control 33 (2009), 1263-1277.

Li, G., R. Schoeni, S. Danziger and K. K. Charles, "New Expenditures Data in the PSID: Comparisons with the CE," Monthly Labor Review 133 (2010), 29-39.

Mian, A., K. RaO And A. Sufi, "House Balance Sheets, Consumption, and the Economic Slump," Quarterly Journal of Economics 128 (2013), 1687-1726.

Mian, A. And A. Sufi, "House Prices, Home Equity-Based Borrowing, and the US Household Leverage Crisis," American Economic Review 101 (2011), 2132-2156.

-, "House Price Gains and U.S. Household Spending from 2002 to 2006," NBER Working Paper No. 20152, 2014.

NAM, T., "Cash-out Refinancing as a Tool for Portfolio Rebalancing," Unpublished, 2015.

Ortalo-Magne, F. and S. Rady, "Boom in, Bust out: Young Households and the Housing Price Cycle," European Economic Reviews 43 (1999), 755-766.

-, "Housing Market Dynamics: On the Contribution of Income Shocks and Credit Constraints," Review of Economic Studies 73 (2006), 459-485. 
Pfeffer, F., R. Schoeni, A. Kennickell and P. Andreski, "Measuring Wealth and Wealth Inequality: Comparing Two U.S. Surveys," Journal of Economic and Social Measurement 41 (2016), 103-120.

Smith, M., "What Do We Know about Equity Withdrawal by Households in New Zealand?," The Blackwell Companion to the Economics of Housing: The Housing Wealth of Nations (2010), 176-200.

Tauchen, G., "Finite State Markov-Chain Approximations to Univariate and Vector Autoregressions," Economics Letters 20 (1986), 177-181.

Wilson, T., "What the Consumer Expenditure Survey Tells Us about Mortgage Instruments before and after the Housing Collapse," Beyond the Numbers: Prices $\&$ Spending 5 (2016), (U.S. Bureau of Labor Statistics).

Wong, A., "Population Aging and the Transmission of Monetary Policy to Consumption," Unpublished, 2015.

YANG, F., "Consumption over the Life Cycle: How Different Is Housing?," Review of Economic Dynamics 12 (2009), 423-443. 
Figure 1: Home equity cashed out, consumption, and residential investment (aggregate data)
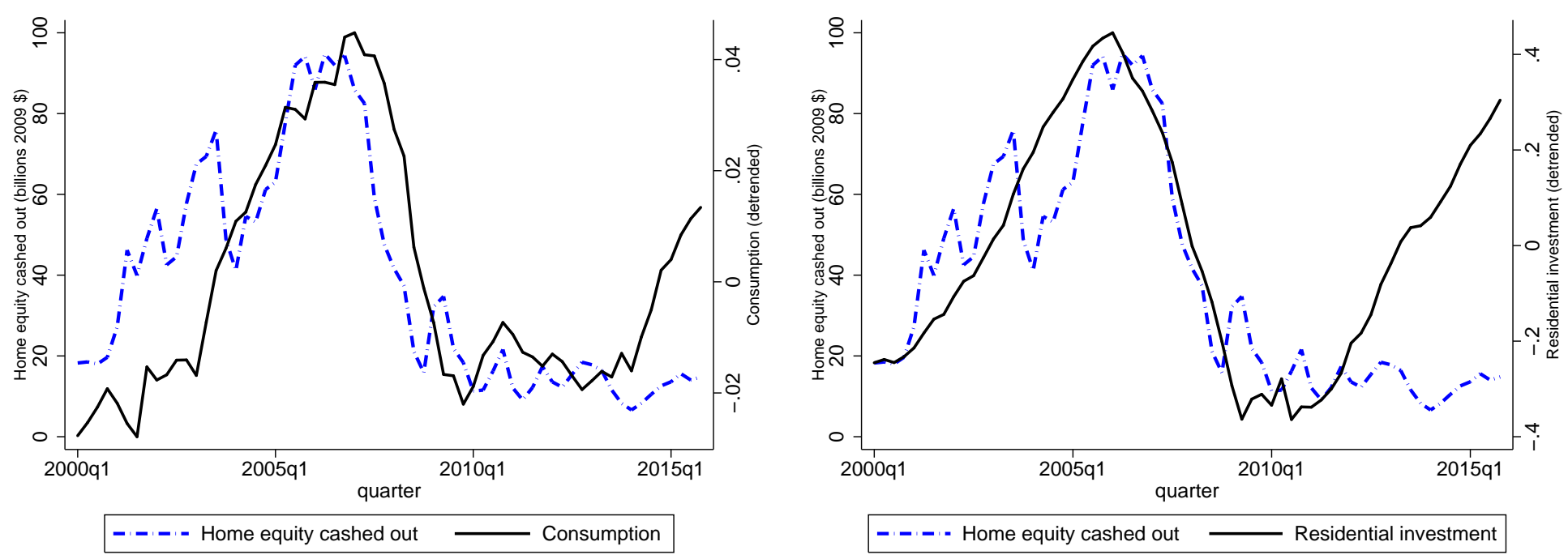

Notes: Data on quarterly real consumption and residential investment are obtained from the BEA NIPA tables, and are log-linearly detrended. The right axis of both figures shows log deviations from the trend. The volume of home equity cashed out is the sum of home equity cashed out through cash-out refinancing, second mortgages, and HELOC, as reported in Freddie Mac's quarterly refinance report. All nominal series are converted to 2009 dollars using the CPI.

Figure 2: Change in expenditures for a one-dollar increase in mortgage debt (micro data)
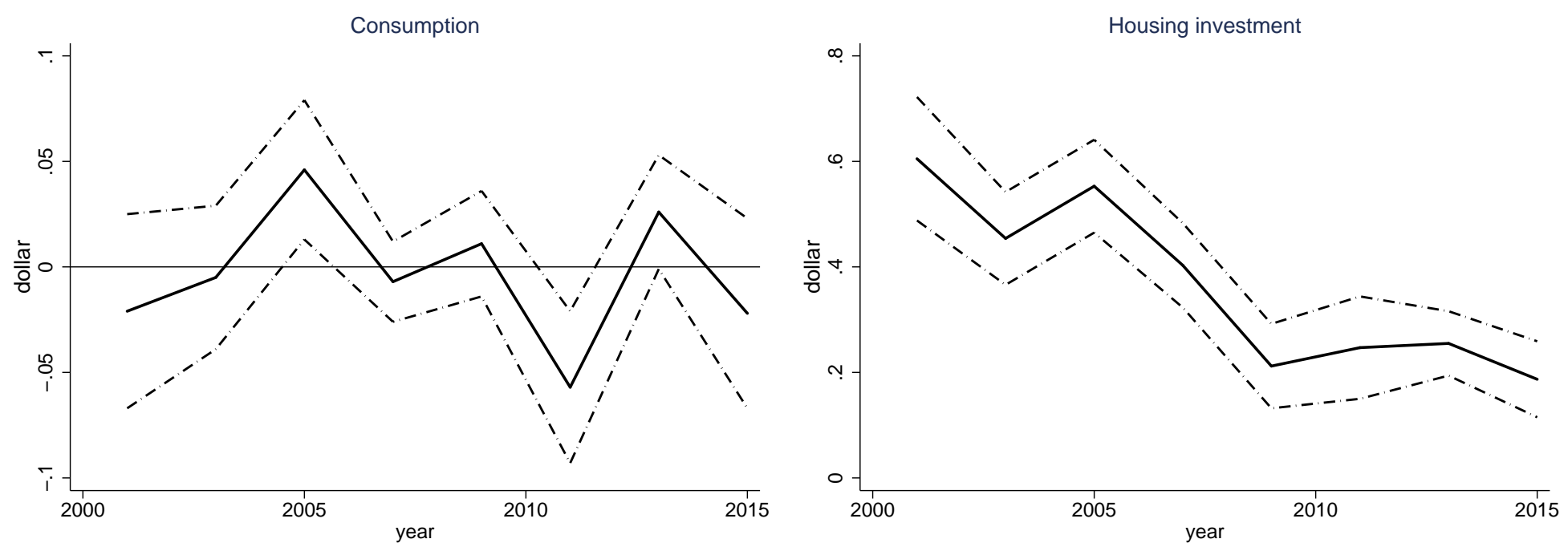

Notes: These estimates are obtained from the household-level regression model (3). The solid lines show the estimated coefficients. The dotted lines show one-standard-deviation confidence intervals. Consumption includes expenditures on non-durable goods, durable goods, and services excluding mortgage payments. Housing investment includes expenditures on the move-up type of investment, home improvement, and net investment expenditures on real estate. See Appendix A for a detailed data description. 
Figure 3: Life-cycle profiles averaged across households in the same age group
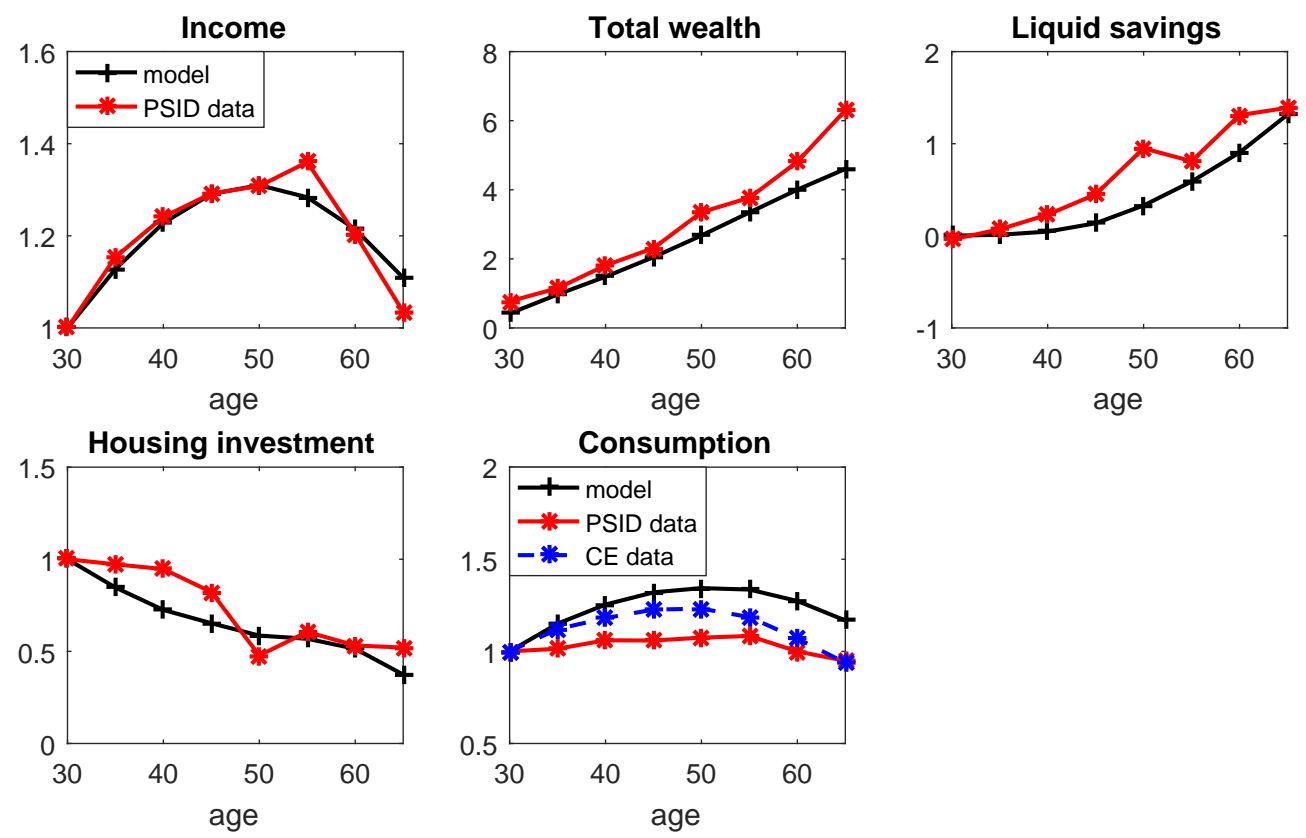

Notes: This figure plots life-cycle profiles simulated by the model and constructed from survey data. The income of the youngest age group, 26-30, is normalized to 1. Total wealth and liquid savings are in proportion to the income of the youngest age group. Housing investment and consumption expenditures are normalized by the corresponding expenditures of the youngest age group.

Figure 4: Impact responses to a $1 \%$ permanent increase in the house price
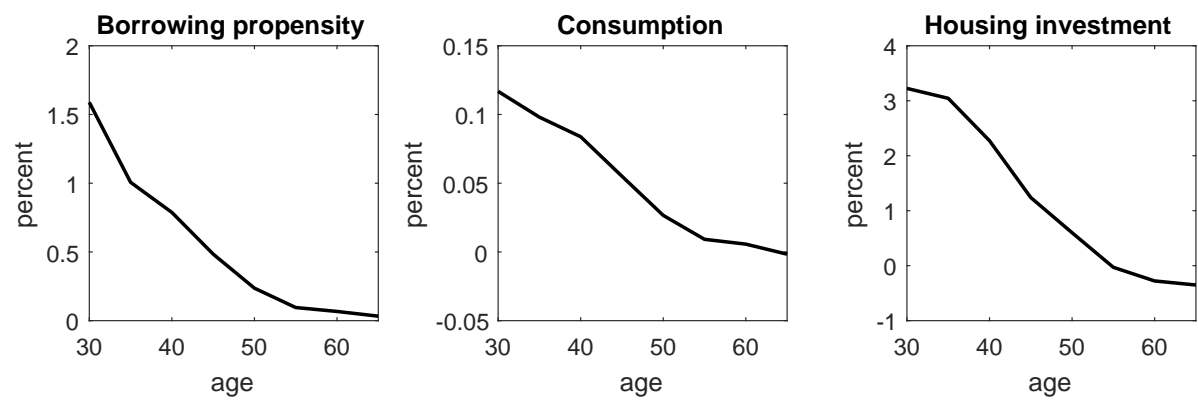

Figure 5: Differential responses to a permanent house price increase
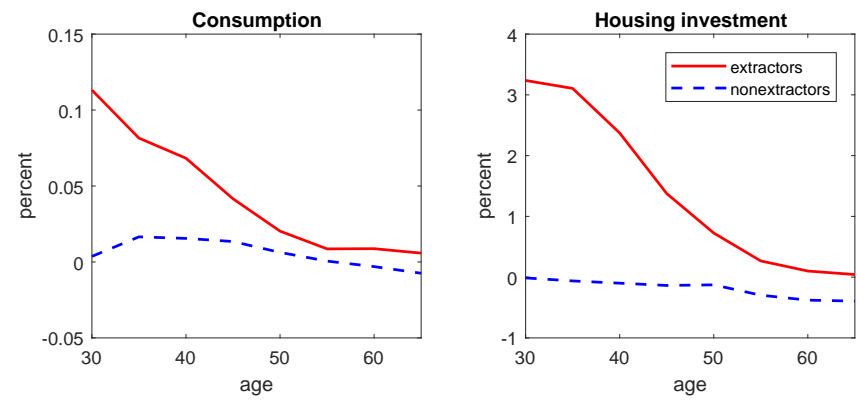
Figure 6: Impact responses to a 1 percentage-point permanent reduction in the mortgage rate
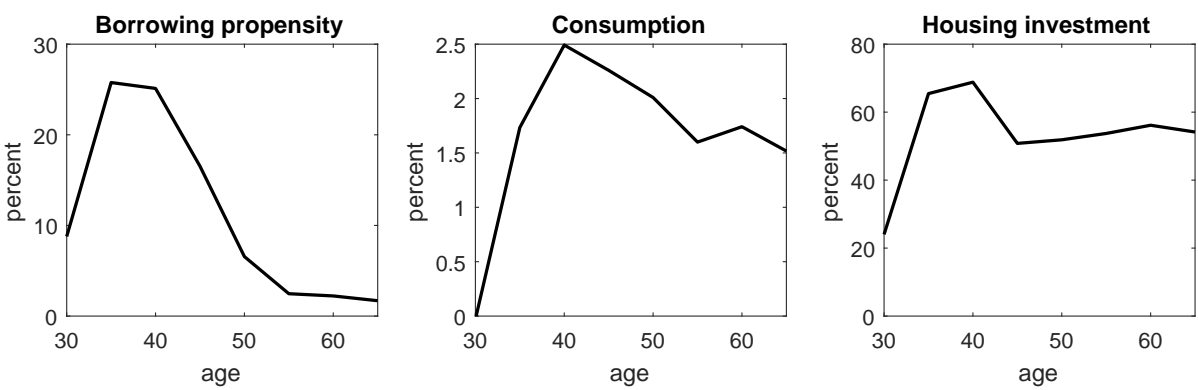

Figure 7: Differential responses to a permanent mortgage rate reduction
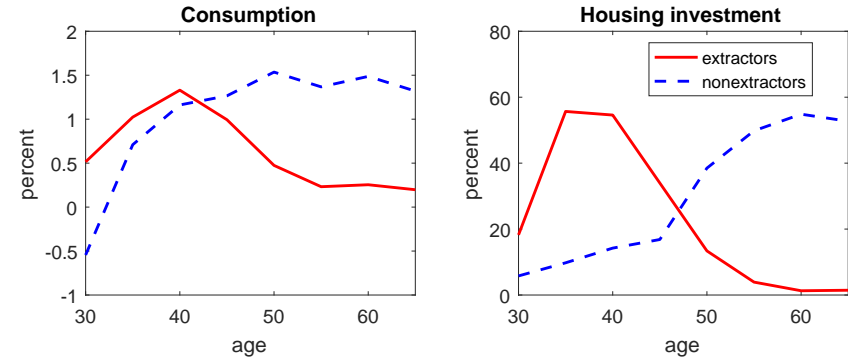

Figure 8: The U.S. boom-bust cycles in the 2000s
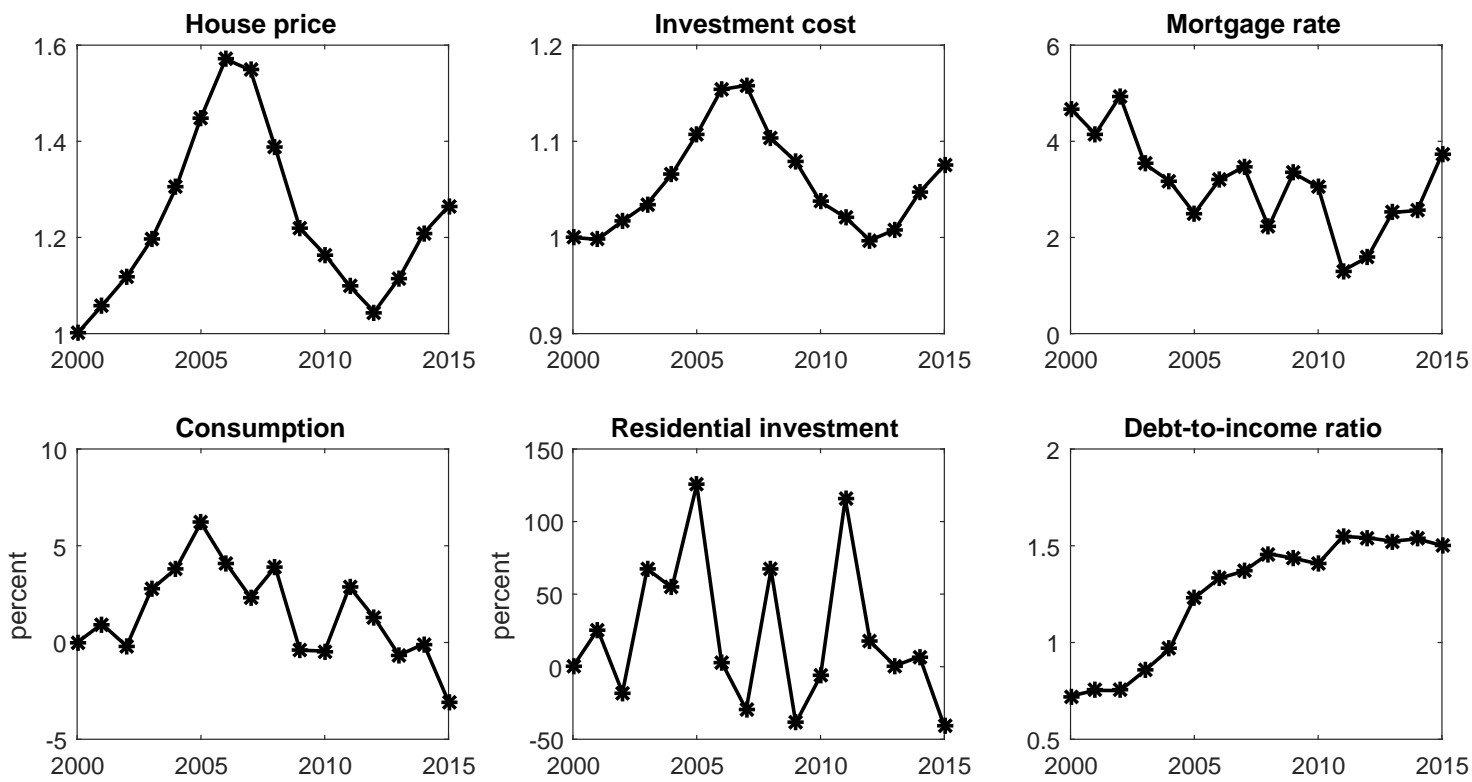

Notes: The upper panel plots historical time series for the real house price index, the real price index for residential structures, and real mortgage rates. The lower panel plots simulated paths obtained by feeding the historical time series in the upper panel into the calibrated model. Consumption and residential investment are expressed in percent deviations from the corresponding value in the year 2000. 
Figure 9: The boom-bust cycle in consumption and residential investment
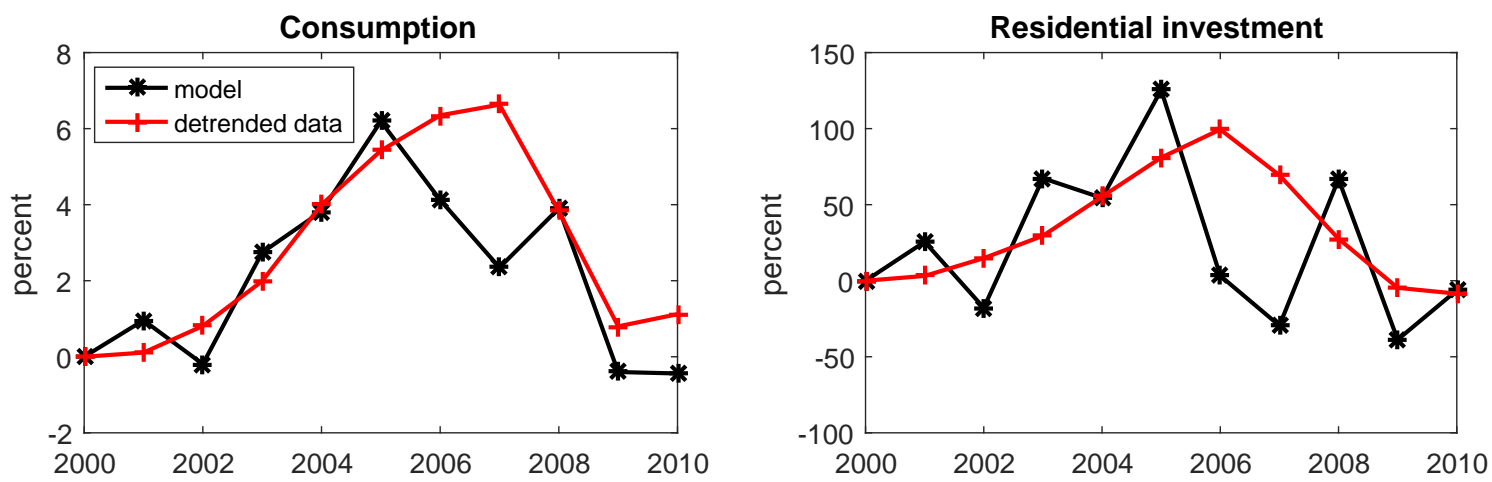

Notes: This figure plots consumption and residential investment simulated by the model, and log-linearly detrended real personal consumption expenditures and residential investment from BEA NIPA data. All series are expressed as the percent deviations from the corresponding value in 2000 .

Figure 10: Policy experiments
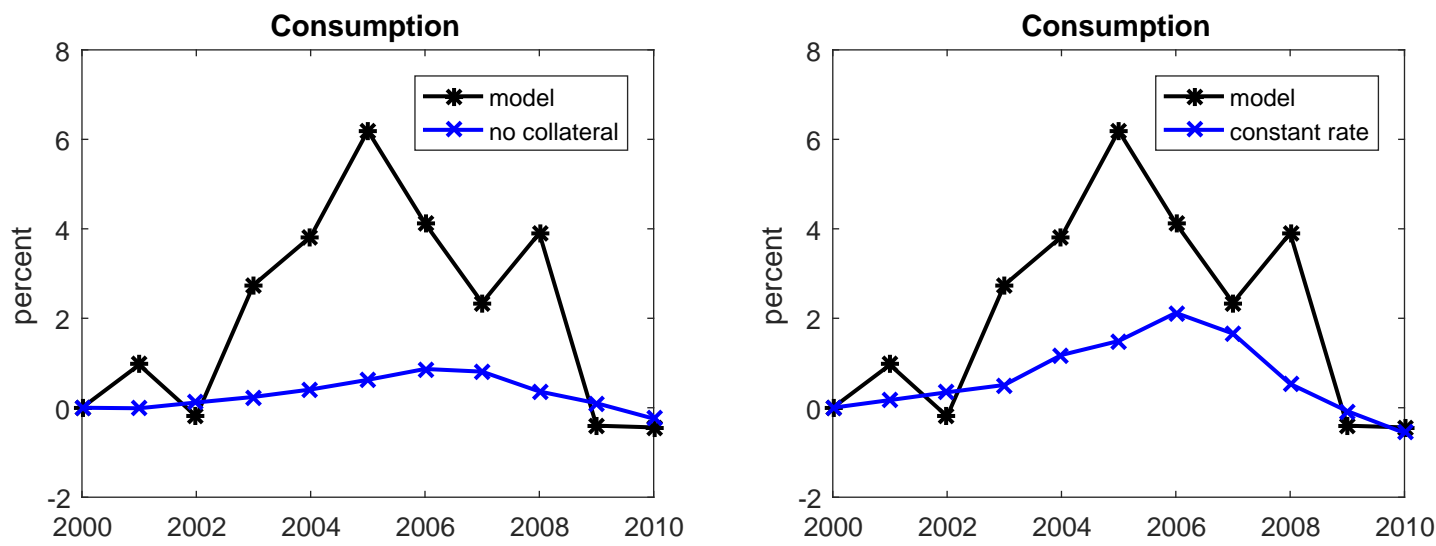

Notes: This figure plots consumption in the model and in two counterfactual analyses. The counterfactual in the left panel represents the experiment where houses have no collateral value but only serve as a consumption good. The counterfactual in the right panel represents the experiment where the mortgage rate is held constant through the cycle at the value of the year 2000 . 


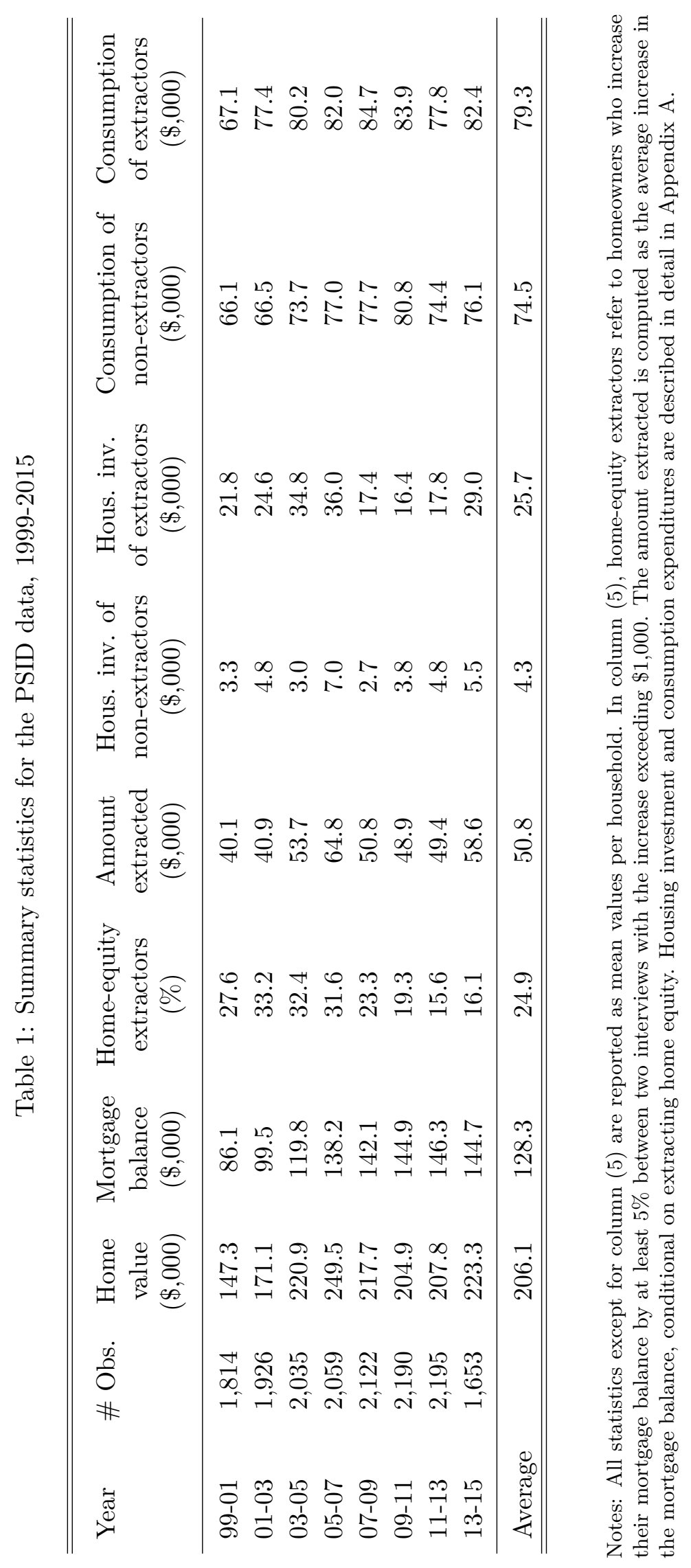


Table 2: Increased mortgage debt and residential investment

\begin{tabular}{|c|c|c|c|c|c|}
\hline & All homeowners & $26-35$ & $36-45$ & $46-55$ & $56-65$ \\
\hline & \multicolumn{5}{|c|}{ i. Propensity to make any type of housing investment } \\
\hline Extract $=1$ & $\begin{array}{c}0.123^{* *} \\
(0.006)\end{array}$ & $\begin{array}{c}0.208^{* *} \\
(0.013)\end{array}$ & $\begin{array}{c}0.137^{* *} \\
(0.011)\end{array}$ & $\begin{array}{c}0.089^{* *} \\
(0.010)\end{array}$ & $\begin{array}{c}0.082^{* *} \\
(0.013)\end{array}$ \\
\hline \multirow[t]{2}{*}{ \# Obs. } & 15,994 & 2,530 & 4,327 & 5,201 & 3,936 \\
\hline & \multicolumn{5}{|c|}{ ii. Propensity to upgrade home } \\
\hline Extract $=1$ & $\begin{array}{c}0.085^{* *} \\
(0.004)\end{array}$ & $\begin{array}{c}0.202^{* *} \\
(0.014)\end{array}$ & $\begin{array}{c}0.112^{* *} \\
(0.009)\end{array}$ & $\begin{array}{c}0.048^{* *} \\
(0.006)\end{array}$ & $\begin{array}{c}0.028 * * \\
(0.005)\end{array}$ \\
\hline \multirow[t]{2}{*}{ \# Obs. } & 15,994 & 2,530 & 4,327 & 5,201 & 3,936 \\
\hline & \multicolumn{5}{|c|}{ iii. Propensity to make home improvements } \\
\hline Extract $=1$ & $\begin{array}{c}0.051^{* *} \\
(0.005)\end{array}$ & $\begin{array}{c}0.064^{* *} \\
(0.012)\end{array}$ & $\begin{array}{c}0.045^{* *} \\
(0.010)\end{array}$ & $\begin{array}{c}0.042^{* *} \\
(0.009)\end{array}$ & $\begin{array}{c}0.060^{* *} \\
(0.012)\end{array}$ \\
\hline \# Obs. & 15,994 & 2,530 & 4,327 & 5,201 & 3,936 \\
\hline \multicolumn{6}{|c|}{ iv. Propensity to invest in real estate } \\
\hline Extract $=1$ & $\begin{array}{c}0.012^{* *} \\
(0.003)\end{array}$ & $\begin{array}{c}0.012 \\
(0.007)\end{array}$ & $\begin{array}{c}0.016^{* *} \\
(0.005)\end{array}$ & $\begin{array}{c}0.013^{*} \\
(0.005)\end{array}$ & $\begin{array}{c}0.008 \\
(0.006)\end{array}$ \\
\hline \# Obs. & 15,994 & 2,530 & 4,327 & 5,201 & 3,936 \\
\hline
\end{tabular}

Notes: A column in each panel presents the results from estimating one logit specification in equation (1). The logit model coefficients are presented as marginal effects. * and ** represent significance at the $5 \%$ and $1 \%$ level, respectively. Sample period: 1999-2015. Standard errors are clustered at the household level. All specifications control for (1) demographics (household head's age, age-squared, and the change in family size); (2) households' financial conditions (the growth rate of income, lagged income, lagged liquid assets, and lagged illiquid assets); and (3) year dummies. Income and wealth variables are converted to 2009 dollars using the CPI. 


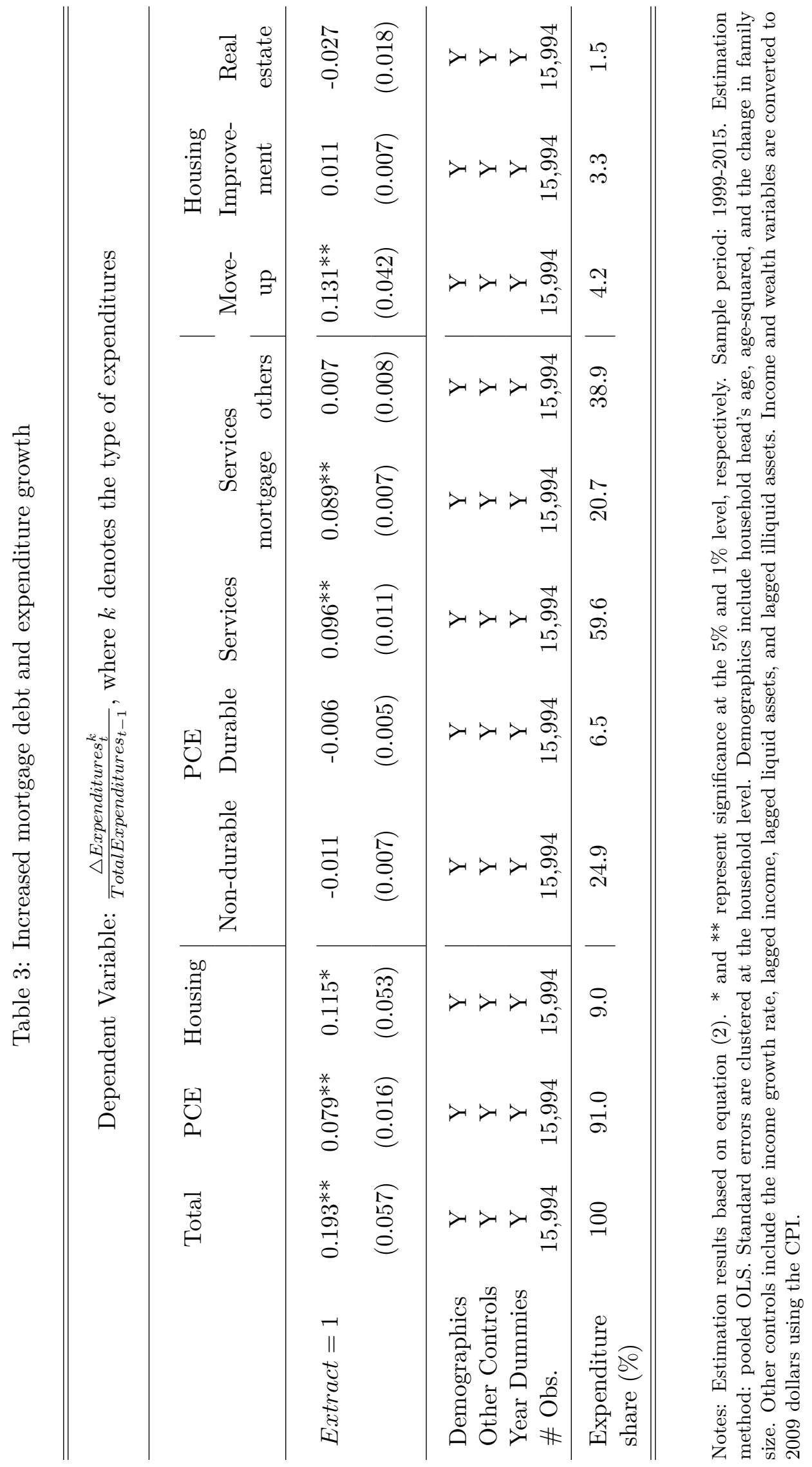


Table 4: Increased mortgage debt and the growth of housing investment

\begin{tabular}{lccccc}
\hline \hline & \multicolumn{4}{c}{ Dependent Variable: growth of housing investment expenditures } \\
& All homeowners & $26-35$ & $36-45$ & $46-55$ & $56-65$ \\
\hline Extract $=1$ & $0.115^{*}$ & $0.279^{* *}$ & 0.056 & $0.060^{*}$ & 0.160 \\
& $(0.053)$ & $(0.073)$ & $(0.160)$ & $(0.026)$ & $(0.086)$ \\
\hline Demographics & $\mathrm{Y}$ & $\mathrm{Y}$ & $\mathrm{Y}$ & $\mathrm{Y}$ & $\mathrm{Y}$ \\
Other Controls & $\mathrm{Y}$ & $\mathrm{Y}$ & $\mathrm{Y}$ & $\mathrm{Y}$ & $\mathrm{Y}$ \\
Year Dummies & $\mathrm{Y}$ & $\mathrm{Y}$ & $\mathrm{Y}$ & $\mathrm{Y}$ & $\mathrm{Y}$ \\
\# Obs. & 15,994 & 2,530 & 4,327 & 5,201 & 3,936 \\
\hline \hline
\end{tabular}

Notes: See Table 3. 


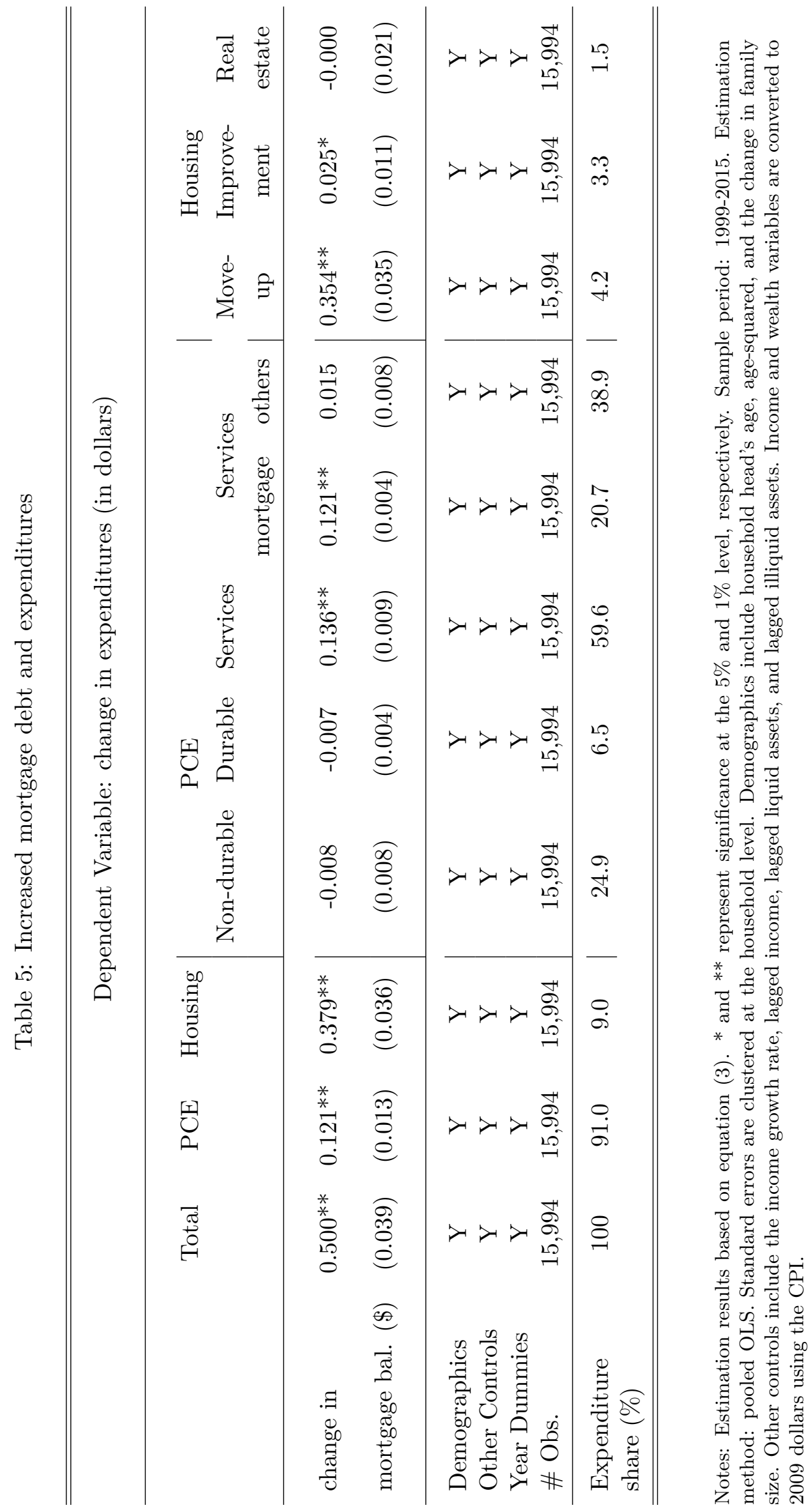


Table 6: Increased mortgage debt and housing investment expenditures

\begin{tabular}{lccccc}
\hline \hline & \multicolumn{5}{c}{ Dependent Variable: change (in dollars) in housing investment } \\
& All homeowners & $26-35$ & $36-45$ & $46-55$ & $56-65$ \\
\hline change in & $0.379^{* *}$ & $0.630^{* *}$ & $0.524^{* *}$ & $0.251^{* *}$ & 0.127 \\
mortgage bal. (\$) & $(0.036)$ & $(0.063)$ & $(0.065)$ & $(0.053)$ & $(0.080)$ \\
\hline Demographics & $\mathrm{Y}$ & $\mathrm{Y}$ & $\mathrm{Y}$ & $\mathrm{Y}$ & $\mathrm{Y}$ \\
Other Controls & $\mathrm{Y}$ & $\mathrm{Y}$ & $\mathrm{Y}$ & $\mathrm{Y}$ & $\mathrm{Y}$ \\
Year Dummies & $\mathrm{Y}$ & $\mathrm{Y}$ & $\mathrm{Y}$ & $\mathrm{Y}$ & $\mathrm{Y}$ \\
\# Obs. & 15,994 & 2,530 & 4,327 & 5,201 & 3,936 \\
\hline \hline
\end{tabular}

Notes: See Table 5 .

Table 7: House price shocks and borrowing propensity

\begin{tabular}{lccccc}
\hline \hline & \multicolumn{5}{c}{ Dependent Variable: Extract $=1$} \\
& All homeowners & $26-35$ & $36-45$ & $46-55$ & $56-65$ \\
\hline House price & $0.266^{* *}$ & $0.508^{* *}$ & $0.341^{* *}$ & $0.172^{* *}$ & $0.143^{* *}$ \\
growth (\%) & $(0.013)$ & $(0.033)$ & $(0.030)$ & $(0.020)$ & $(0.020)$ \\
\hline Demographics & $\mathrm{Y}$ & $\mathrm{Y}$ & $\mathrm{Y}$ & $\mathrm{Y}$ & $\mathrm{Y}$ \\
Other Controls & $\mathrm{Y}$ & $\mathrm{Y}$ & $\mathrm{Y}$ & $\mathrm{Y}$ & $\mathrm{Y}$ \\
Year Dummies & $\mathrm{Y}$ & $\mathrm{Y}$ & $\mathrm{Y}$ & $\mathrm{Y}$ & $\mathrm{Y}$ \\
\# Obs. & 15,994 & 2,530 & 4,327 & 5,201 & 3,936 \\
\hline \hline
\end{tabular}

Notes: Estimation results based on equation (4). * and ** represent significance at the $5 \%$ and $1 \%$ level, respectively. The logit model coefficients are presented as marginal effects. Sample period: 1999-2015. Standard errors are clustered at the household level. Demographics include household head's age, age-squared, and the change in family size. Other controls include the income growth rate, lagged income, lagged liquid assets, and lagged illiquid assets. Income and wealth variables are converted to 2009 dollars using the CPI. 
Table 8: The collateral effect of house price shocks

\begin{tabular}{lccccc}
\hline \hline & \multicolumn{5}{c}{ Dependent Variable: Extract $=1$} \\
& All homeowners & $26-35$ & $36-45$ & $46-55$ & $56-65$ \\
\hline House price & $0.130^{* *}$ & $0.154^{* *}$ & $0.139^{* *}$ & $0.091^{* *}$ & $0.138^{* *}$ \\
growth (\%) & $(0.015)$ & $(0.038)$ & $(0.035)$ & $(0.023)$ & $(0.023)$ \\
& & & & & \\
$L T V_{t-1} \times$ House & $0.339^{* *}$ & $0.578^{* *}$ & $0.437^{* *}$ & $0.251^{* *}$ & 0.002 \\
growth $(\%)$ & $(0.037)$ & $(0.077)$ & $(0.078)$ & $(0.059)$ & $(0.036)$ \\
& & & & & \\
$L T V_{t-1}$ & $-0.071^{* *}$ & $-0.256^{* *}$ & $-0.137^{* *}$ & -0.028 & $0.074^{* *}$ \\
& $(0.012)$ & $(0.031)$ & $(0.024)$ & $(0.019)$ & $(0.017)$ \\
\hline Demographics & $\mathrm{Y}$ & $\mathrm{Y}$ & $\mathrm{Y}$ & $\mathrm{Y}$ & $\mathrm{Y}$ \\
Other Controls & $\mathrm{Y}$ & $\mathrm{Y}$ & $\mathrm{Y}$ & $\mathrm{Y}$ & $\mathrm{Y}$ \\
Year Dummies & $\mathrm{Y}$ & $\mathrm{Y}$ & $\mathrm{Y}$ & $\mathrm{Y}$ & $\mathrm{Y}$ \\
\# Obs. & 15,994 & 2,530 & 4,327 & 5,201 & 3,936 \\
\hline \hline
\end{tabular}

Notes: See Table 7.

Table 9: Mortgage rate shocks and borrowing propensity

\begin{tabular}{lccccc}
\hline \hline & \multicolumn{5}{c}{ Dependent Variable: Extract $=1$} \\
& All homeowners & $26-35$ & $36-45$ & $46-55$ & $56-65$ \\
\hline$r_{t-1}^{b}$ & $0.851^{* *}$ & 0.439 & $1.383^{* *}$ & $1.143^{* *}$ & 0.012 \\
(p.p.) & $(0.244)$ & $(0.576)$ & $(0.431)$ & $(0.401)$ & $(0.483)$ \\
& & & & & \\
House price & $0.434^{* *}$ & $0.662^{* *}$ & $0.506^{* *}$ & $0.305^{* *}$ & $0.252^{* *}$ \\
growth (\%) & $(0.018)$ & $(0.035)$ & $(0.034)$ & $(0.032)$ & $(0.039)$ \\
\hline Demographics & $\mathrm{Y}$ & $\mathrm{Y}$ & $\mathrm{Y}$ & $\mathrm{Y}$ & $\mathrm{Y}$ \\
Other Controls & $\mathrm{Y}$ & $\mathrm{Y}$ & $\mathrm{Y}$ & $\mathrm{Y}$ & $\mathrm{Y}$ \\
Year Dummies & $\mathrm{Y}$ & $\mathrm{Y}$ & $\mathrm{Y}$ & $\mathrm{Y}$ & $\mathrm{Y}$ \\
\# Obs. & 11,837 & 2,178 & 3,535 & 3,762 & 2,362 \\
\hline \hline
\end{tabular}

Notes: Estimation results based on equation (5). * and ** represent significance at the $5 \%$ and $1 \%$ level, respectively. The logit model coefficients are presented as marginal effects. Sample period: 1999-2015. Standard errors are clustered at the household level. Demographics include household head's age, age-squared, and the change in family size. Other controls include the income growth rate, lagged income, lagged liquid assets, and lagged illiquid assets. Income and wealth variables are converted to 2009 dollars using the CPI. 
Table 10: Calibration

\begin{tabular}{|c|c|c|}
\hline Parameter & & Value \\
\hline \multicolumn{3}{|l|}{ Preference } \\
\hline$u(c, h)$ & Utility function & $\underline{\left(c^{\alpha} h^{1-\alpha}\right)^{1-\sigma}}$ \\
\hline$\sigma$ & Inverse of IES & 2 \\
\hline$\beta$ & Discount factor & 0.935 \\
\hline$\alpha$ & Non-housing expenditure share & 0.81 \\
\hline$\eta$ & Utility weight on bequest & 6 \\
\hline \multicolumn{3}{|l|}{ Income } \\
\hline $\log (y)$ & Log income process & $\chi+z$ \\
\hline$\chi$ & Deterministic age-specific income & \\
\hline$z$ & Idiosyncratic income shocks & $\mathrm{AR}(1)$ \\
\hline$\rho_{z}$ & Persistence of $z$ & 0.9 \\
\hline$\sigma_{e z}$ & Standard deviation of $z$ 's error term & 0.18 \\
\hline$\zeta$ & $\begin{array}{l}\text { Retirement income as a fraction of } \\
\text { the last working period's income }\end{array}$ & 0.6 \\
\hline \multicolumn{3}{|c|}{ Housing and Mortgage } \\
\hline $\bar{\delta}$ & Housing depreciation rate & 0.0227 \\
\hline$\theta$ & Down payment rate & 0.25 \\
\hline$F$ & Loan adjustment cost & 0.025 \\
\hline \multicolumn{3}{|c|}{$\underline{\text { Aggregate Variables }}$} \\
\hline $\bar{p}$ & Steady state house price & 1 \\
\hline$p^{I}$ & Steady state housing investment cost & 1 \\
\hline$r^{b}$ & Steady state mortgage rate & 0.04 \\
\hline$r^{a}$ & Interest rate of liquid savings & 0.01 \\
\hline
\end{tabular}

Notes: This table shows calibrated parameters. See Section 4 for method description. 
Table 11: Increased mortgage debt and residential investment (model simulation)

\begin{tabular}{lccccc}
\hline \hline & \multicolumn{5}{c}{ Dependent Variable: Invest $=1$} \\
& All homeowners & $26-35$ & $36-45$ & $46-55$ & $56-65$ \\
\hline Extract $=1$ & $0.132^{* *}$ & $0.191^{* *}$ & $0.138^{* *}$ & -0.001 & $-0.417^{* *}$ \\
& $(0.004)$ & $(0.008)$ & $(0.008)$ & $(0.013)$ & $(0.049)$ \\
\hline Demographics & $\mathrm{Y}$ & $\mathrm{Y}$ & $\mathrm{Y}$ & $\mathrm{Y}$ & $\mathrm{Y}$ \\
Other Controls & $\mathrm{Y}$ & $\mathrm{Y}$ & $\mathrm{Y}$ & $\mathrm{Y}$ & $\mathrm{Y}$ \\
\# Obs. & 140,400 & 32,400 & 36,000 & 36,000 & 36,000 \\
\hline \hline
\end{tabular}

Notes: Estimation results based on equation $\left(1^{\prime}\right)$ using simulated data from the calibrated model. * and ** represent significance at the $5 \%$ and $1 \%$ level, respectively. The logit model coefficients are presented as marginal effects. Robust standard errors are in parentheses. Demographics include household's age and age-squared. Other controls include the income growth rate, lagged income, lagged liquid assets, and lagged illiquid assets. The age group 26-35 has a smaller sample size because the variable Extract=1 is constructed by taking differences in the borrowing amount.

Table 12: Increased mortgage debt and expenditure growth (model simulation)

\begin{tabular}{lccc|cccc}
\hline \hline & \multicolumn{5}{c}{ Dependent Variable: $\triangle$ Expenditures $_{j}^{k} /$ TotalExpenditures $_{j-1}$} \\
& Total & Consumption & Housing & \multicolumn{4}{c}{ Housing investment } \\
& & & investment & $26-35$ & $36-45$ & $46-55$ & $56-65$ \\
\hline Extract $=1$ & $0.142^{* *}$ & $0.021^{* *}$ & $0.122^{* *}$ & $0.169^{* *}$ & $0.129^{* *}$ & $0.077^{* *}$ & $0.014^{* *}$ \\
& $(0.001)$ & $(0.001)$ & $(0.001)$ & $(0.002)$ & $(0.003)$ & $(0.003)$ & $(0.002)$ \\
\hline Demographics & $\mathrm{Y}$ & $\mathrm{Y}$ & $\mathrm{Y}$ & $\mathrm{Y}$ & $\mathrm{Y}$ & $\mathrm{Y}$ & $\mathrm{Y}$ \\
Other Controls & $\mathrm{Y}$ & $\mathrm{Y}$ & $\mathrm{Y}$ & $\mathrm{Y}$ & $\mathrm{Y}$ & $\mathrm{Y}$ & $\mathrm{Y}$ \\
\# Obs. & 140,400 & 140,400 & 140,400 & 32,400 & 36,000 & 36,000 & 36,000 \\
\hline \hline
\end{tabular}

Notes: Estimation results based on equation $\left(2^{\prime}\right)$. Estimation method: OLS. Otherwise as in Table 11.

Table 13: Increased mortgage debt and expenditures (model simulation)

\begin{tabular}{|c|c|c|c|c|c|c|c|}
\hline & \multicolumn{7}{|c|}{ Dependent Variable: change (in dollars) } \\
\hline & \multirow[t]{2}{*}{ Total } & \multirow[t]{2}{*}{ Consumption } & \multirow{2}{*}{$\begin{array}{c}\text { Housing } \\
\text { investment }\end{array}$} & \multicolumn{4}{|c|}{ Housing investment } \\
\hline & & & & $26-35$ & $36-45$ & $46-55$ & $56-65$ \\
\hline change in & $0.506^{* *}$ & $0.057^{* *}$ & $0.449^{* *}$ & $0.777^{* *}$ & $0.607 * *$ & $0.376^{* *}$ & $0.183^{* *}$ \\
\hline mortgage balance $(\$)$ & $(0.006)$ & $(0.001)$ & $(0.005)$ & $(0.007)$ & $(0.010)$ & $(0.011)$ & $(0.010)$ \\
\hline Dem & $\mathrm{Y}$ & Y & $\mathrm{Y}$ & $\mathrm{Y}$ & $\mathrm{Y}$ & $\mathrm{Y}$ & $\mathrm{Y}$ \\
\hline Other Controls & $\mathrm{Y}$ & Y & $\mathrm{Y}$ & Y & $\mathrm{Y}$ & $\mathrm{Y}$ & $\mathrm{Y}$ \\
\hline \# Obs. & 140,400 & 140,400 & 140,400 & 32,400 & 36,000 & 36,000 & 36,000 \\
\hline
\end{tabular}

Notes: Estimation results based on equation $\left(3^{\prime}\right)$. Estimation method: OLS. Otherwise as in Table 11. 


\section{Appendices}

\section{A Data and Variable Description}

Variables in the PSID The PSID family survey data from 1999 to 2015 can be downloaded from the PSID data center of the Institute for Social Research at the University of Michigan. Below I describe the definition of the key variables used in Section 2.

- Home value: The market value of the primary residence, estimated by the homeowner.

- Total mortgage balance: The sum of the remaining principal owed on the first and the second mortgage that are tied to the primary residence. Note that the PSID does not solicit mortgage information related to a second home or real estate properties.

- Housing investment expenditures:

1. Move-up: Expenditures of this type of investment are computed as the difference between the estimated value of the current home and the price at which the old home was sold. Note that the PSID does not inquire about the purchase price of the current home.

2. Home improvement: Expenditures are estimated by the homeowner who made additions or improvements to any homes owned since the last interview that exceeded $\$ 10,000$. General maintenance or upkeep is not included.

3. Investment on second homes or real estate: Expenditures are computed as the difference between the amount used to buy and the amount acquired from selling real estate other than the primary residence of the respondent household, since the last interview.

- Personal consumption expenditures:

1. Non-durable goods: The sum of food (at home, delivered, and eaten out) and gasoline expenditures. Expenditures on clothing have been available since 2005.

2. Durable goods: The purchase price of the vehicles bought by the household. Expenditures on furniture, trips, and recreation have been available since 2005 .

3. Services: Expenditures on utilities (heating, electricity, water, and other kinds of utilities), education, health (hospital bills, doctor visits, prescription drugs, and health insurance), child care, vehicle lease (lease payment and fees), public transportation (bus, train, taxi, and other transportation services), parking, vehicle repair, vehicle insurance, 
homeowner insurance, property tax, and mortgage payments (sum of the payments for the first and the second mortgage that are tied to the primary residence). Expenditures on telephone, internet, and home repair services are available since 2005.

- Income: Total family income includes the household head's and the spouse's taxable income, transfer income, and social security income.

- Wealth consists of liquid assets and illiquid assets:

- Liquid assets include safe liquid assets (the amount in checking and savings accounts, money market funds, certificates of deposit, government savings bonds, and treasury bills) and risky assets (stock shares), net of other non-mortgage debt (credit card charges, student loans, medical or legal bills, and loans from relatives).

- Illiquid assets include home equity (home value subtracted by the total mortgage balance), the net value of owned real estate, amount in private annuities and individual retirement accounts, the net value of other assets, and the value of farms or businesses.

\section{Historical Time Series Data}

- House price index: The S\&P CoreLogic Case-Shiller U.S. National Home Price Indices downloaded from FRED.

- Residential structure cost: The price index for residential structures are obtained from the Land and Property Values in the U.S., Lincoln Institute of Land Policy. ${ }^{32}$ The series is constructed by Davis and Heathcote (2007) based on the estimates of the replacement cost of residential structures. These estimates differ from BEA published values. Specifically, the estimates exclude (a) all residential equipment; (b) the replacement cost of residential farm structures; (c) mobile homes; (d) structures owned by non-profits; and (e) broker's commissions.

- Mortgage rate: The 30-year fixed rate mortgage average downloaded from FRED.

- CPI: CPI for all items and CPI less food and energy downloaded from FRED.

- Consumption: Personal consumption expenditures from the BEA NIPA.

- Residential Investment: Private residential fixed investment expenditures from BEA NIPA.

\footnotetext{
${ }^{32}$ http://www.lincolninst.edu/resources/.
} 


\section{B Numerical Solution Methods}

In this Appendix, I describe the two-step numerical procedure used to solve the model. I assume that the aggregate state, $S \equiv\left(p, p^{I}, r^{b}\right)$, is set to its steady state value. In the first step, I solve value functions over a fixed-grid state space. In the second step, given the realized state, I solve the optimal choices over a finer choice set and use linear interpolation to compute the continuation value. $^{33}$

To obtain the value functions, I discretize the state space $(h, b, a, y)$. I choose 20 grids for the endogenous state variables $h$ and $b$ and 10 grids for $a$. For the stochastic component of $y$, I use the Tauchen (1986) method to discretize an AR(1) process to 5 states. The Tauchen method chooses grid points and computes the corresponding transitional probability matrix. I use the following backward-induction algorithm to solve the value functions.

1. The value function of the last period is pinned down by the bequest function.

2. For each period $j$, given each possible state $(h, b, a, y)$, I compute $V_{j}^{C}(h, b, a, y)$ and $V_{j}^{N}(h, b, a, y)$ separately. To obtain $V_{j}^{C}(h, b, a, y)$, I construct a choice set $\left\{h_{C}^{\prime}(h, b, a, y), b_{C}^{\prime}(h, b, a, y), a_{C}^{\prime}(h, b, a, y)\right\}$. The choice set taking all constraints in Problem (6) into account may vary across states. The choices are spaced more closely to the constraints of $h_{C}^{\prime}$ and $b_{C}^{\prime}$.

3. I compute the value of the objective function as in Problem (6) for each choice, and use linear interpolation to compute the continuation value if the choice is not on the grid points.

4. I compare the value of the objective function across all choices, and set $V_{j}^{C}(h, b, a, y)$ to the largest value.

5. A similar procedure based on point $2-4$ can be used to obtain $V_{j}^{N}(h, b, a, y)$. I set $V_{j}(h, b, a, y)=\max \left\{V_{j}^{C}(h, b, a, y), V_{j}^{N}(h, b, a, y)\right\}$.

To obtain optimal choices in the second step, given a realized state $(h, b, a, y)$, I solve the optimization problem using a similar approach as described in point 2-5 above. The difference is that I search over a finer choice set that has 4 times more choices for each variable. This procedure

\footnotetext{
${ }^{33}$ I experimented with alternative interpolation methods, such as the Chebyshev polynomial approximation. Since these methods are designed to approximate smooth functions using smooth functions, the approximation performance is poor, especially at the boundary of the state space, because value functions in my model are not smooth.
} 
allows me to find the solution more precisely.

To obtain impact responses after a permanent shock, I fix individual-specific states at the beginning of the shock period at the value in the original stationary equilibrium state, and solve the value functions and optimal choices with the shock value. To obtain the aggregate response, I average responses across households of the same age, and then average across ages.

\section{Responses to a Simultaneous Shock to $p$ and $p^{I}$}

In this section, I follow the existing literature in assuming that a shock to the house price $p$ is perfectly passed through to the cost of housing investment, $p^{I}$. In other words, the model does not distinguish between $p$ and $p^{I}$. I compute the response of the borrowing propensity, consumption, and housing investment to this shock.

Intuitively, the shock to $p$ affects household decisions through the collateral channel effect as shown in Section 6.1. The shock to $p^{I}$ creates an income and a substitution effect due to the relative price change between the housing and the consumption good, and creates a wealth effect that arises from the proceeds of the net sale of the housing stock.

The left panel of Figure C.1 shows that the shock triggers more homeowners to increase their mortgage debt, especially young homeowners. This result captures the collateral effect of the house price shock, as the response of borrowing is almost the same as that in Figure 4. The middle and right panel show that consumption increases by more than in Section 6.1, whereas housing investment decreases. Recall that the collateral effect due to an increase in $p$ raises both consumption and housing investment. An increase in $p^{I}$ has three effects: (i) the income effect, which decreases both consumption and housing investment expenditures, because housing investment is more expensive; (ii) the substitution effect, which increases consumption and decreases housing investment, as households substitute relatively cheaper consumption goods for more expensive housing services; and (iii) There is no positive wealth effect, since households do not actively downsize their home. Therefore, the shock to $p^{I}$ unambiguously decreases housing investment expenditures, and increases consumption if the substitution effect is strong. The middle panel shows that the response of consumption is a combination of the collateral effect and the substitution effect. The right panel shows that the combined income and substitution effect exceeds the collateral effect and that housing investment expenditures decrease on average. 
Figure C.2 decomposes the responses of consumption and housing investment expenditures between those who increase their mortgage debt and those who do not. Clearly, for those who increase their mortgage debt, the collateral effect still dominates, which drives these households, especially young households, to increase their consumption and housing investment. The substitution effect drives those who do not increase their mortgage to increase consumption, and to reduce their housing investment expenditures.

Figure C.1: Impact responses to a simultaneous permanent increase in the house price and in the investment cost
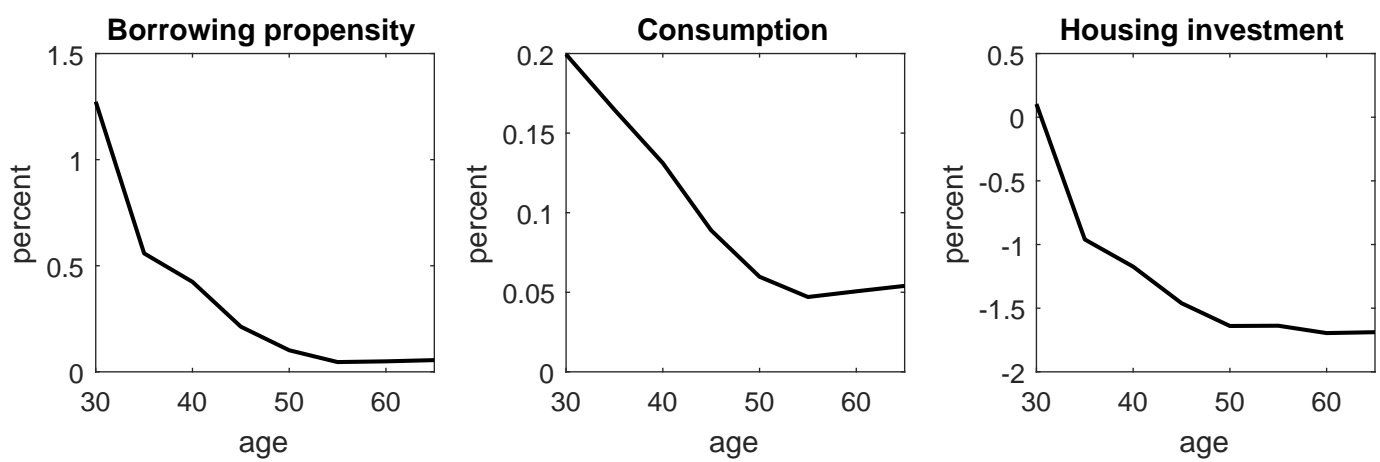

Figure C.2: Differential responses to a simultaneous permanent increase in the house price and in the investment cost
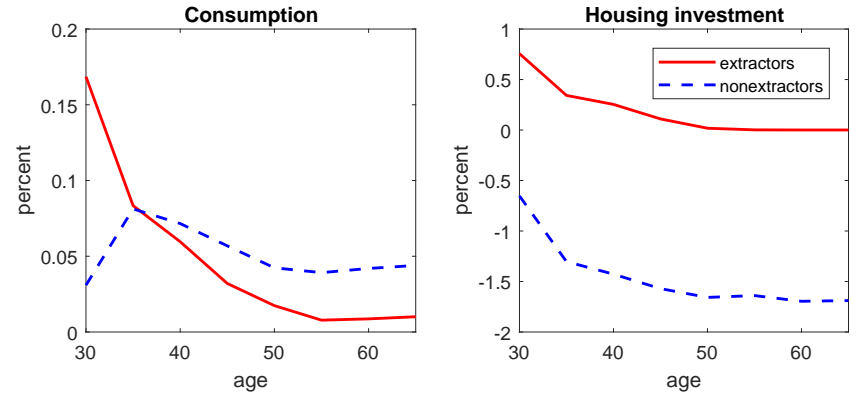

\section{Alternative Expectations Assumption}

In this appendix, I simulate the model for the boom-bust cycle in the 2000s by using an alternative expectations assumption. The purpose of this exercise is to examine whether the fit of the model to the aggregate data is robust to this modification. This assumption differs from Section 7 in that households expect future house prices and home investment costs to grow at the current rate. For example, in a given year, a shock causes the house price to increase by $10 \%$ and the investment cost to increase by $5 \%$. Households expect that future house prices and investment 
costs continue to grow at an annual rate of $10 \%$ and $5 \%$, respectively.

Figure D.1 shows the performance of the model under this alternative expectation assumption. The model generates a boom-bust cycle in consumption and residential investment. It captures the boom in the data before 2006, and the bust after 2008. The magnitude of the deviations are also similar to the data. Overall, the model generates similar movements under two alternative expectation assumptions, especially for consumption.

It is interesting to discuss the difference between the data and model under this expectation assumption, and the difference in the model between the two expectation assumptions. First, note that in 2006 and 2007 consumption fell in the model, unlike in the actual data. As discussed in Section 7 , this is because a rise in the mortgage rate lowered consumption, even though house prices and investment costs were rising. Second, residential investment behaved differently in 2008 under the alternative expectations assumption. Under the baseline assumption in Section 7, residential investment rose because of a drop in the mortgage rate, whereas it falls under the alternative expectation assumptions. This difference is explained by households' expectation about future home investment costs. In 2008, the cost of home investment fell sharply for the first time during the cycle. With the alternative expectations assumption, households expected that the home investment cost would continue to fall in the future. Therefore, they delayed their home investment, even though the mortgage rate was low. This intuition also explains why housing investment fell to a larger extent during the bust.

Figure D.1: The boom-bust cycle in consumption and residential investment (alternative expectations assumption)
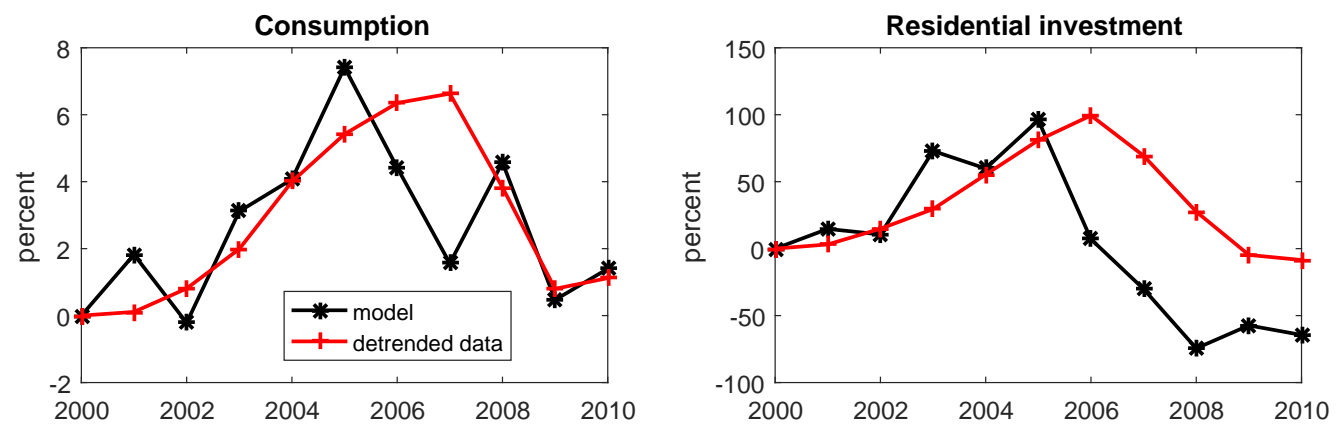

Notes: This figure plots consumption and residential investment simulated from the calibrated model, and log-linearly detrended real personal consumption expenditures and residential investment from BEA NIPA data. All series are expressed as percent deviations from their value in 2000. The model differs from that underlying Figure 9 only in the expectations assumption. 